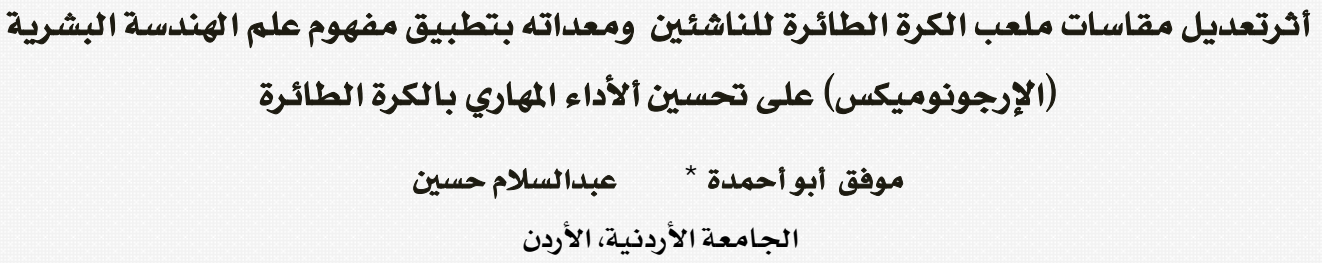

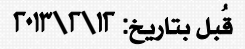

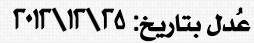

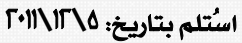

هدفت هذه الدراسة للتعرف إلى أثر تعديل مقاسات ملعب الكرة الطائرة للصغار ، ومعداته بتطبيق مفهوم علم الهندسة البشرية (الإرجونوميكس)، وِّ تحسين ألأداء المهاري بالكرة الطائرة. استخدم الباحثان المنهج التجريبي، وتكونت عينة الدراسة من ·ع

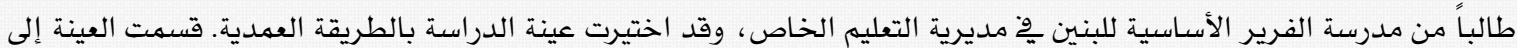
مجموعتين متكافئتين؛ إحداهما تجريبية والأخرى ضابطة. وقد خضعت المجموعتين التجريبية والضابطة، للبرنامج التعليمي المقترح. استخدمت المجموعة التجريبية ملعب الكرة الطائرة المعدل، ومعداته بتطبيق مفهوم علم الهندسة البشرية (الأرجونوميكس) ، أما المجموعة الضابطة فقد استخدمت الملعب القانوني يخ الكرة الطائرة. استفرق تطبيق البرنامج التعليهي المقترح ثمانية أسابيع، بواقع ثلاث وحدات تعليمية وِّ الأسبوع، وكل وحدة تعليمية استغرقت مع دقيقة. أظهرت نتائج الدراسة إلى أن تعديل مقاسات ملعب الكرة الطائرة للناشئين ومعداته بتطبيق الإرجونوميكس، ساهم مِّ تحسين ألأداء المهاري بالكرة الطائرة لدى أفراد المجموعة التجريبية بين القياس القبلي والبعدي ولصالح البعدي. كما أظهرت النتائج أن الملعب القانوني ساهم هِّْ تحسنَ الأداء المهاري بالكرة الطائرة لدى أفراد المجموعة الضابطة بين القياس القبلي والبعدي ولصالح البعدي. وأشارت النتائج إلى أن أثر تعديل مقاسات ملعب الكرة الطائرة للناشئين ومعداته بتطبيق الإرجونوميكس ساهم مِّْ تحسن الأداء المهاري لأفراد المجموعة التجريبية بالمقارنة مع أضراد المجموعة الضابطة ولصالح أفراد المجموعة التجريبية. ويوصي الباحثان باستخدام ملعب

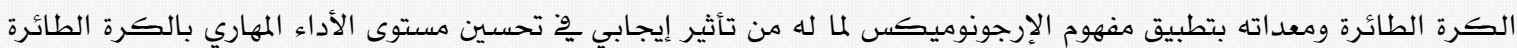

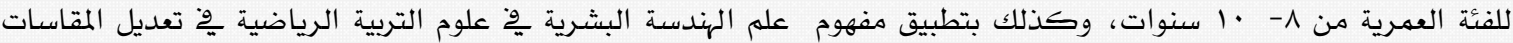
والمعدات بها يتتاسب مع الفئات العهرية.

الكلمات المفتاحية: الهندسة البشرية، الكرة الطائرة، قياسات الملاعب، دراسة تجريبية وِّا الكرة الطائرة.

\title{
The Impact of Modifying the Junior Volleyball Dimensions Court and the Related Equipment By A pplying the Concept of Human Engineering Ergonomics on the Skill Performance in Volleyball
}

\author{
Mwafaq A bu A hmada* A bdel salam Hussain \\ Jordan University, Jordan
}

The purpose of the study was to investigate the impact of modifying the dimensions of junior volleyball court and the related equipment on the skill performance in volleyball by applying the concept of human engineering ergonomics. A purposive sample of 40 male students at Al-Frair basic school was selected. The sample was divided into two groups: experimental group (20) and control group (20). The two groups implemented the suggested learning program with the experimental used the modified volleyball playground, while the control group used ordinary volleyball playground. The learning program lasted 8 weeks / 3 learning sessions per week and that each learning unit lasted 45 minutes. The results show ed that the performance of the experimental group was enhanced significantly compared to the control group in the post test, suggesting the impact of ergonomics in modifying the volleyball play-ground dimensions and the related equipment. The researchers recommend utilizing the modified playground as it reflects significant related skill performance for (8-10) years aged students and to apply the concept of ergonomics in the different PE sciences to modify both dimensions and the related equipment to go with the relevant age group.

Keywords: human engineering, volleyball, playground dimensions, experimental study in volleyball.

*abdelsalam702000@yahoo.com 


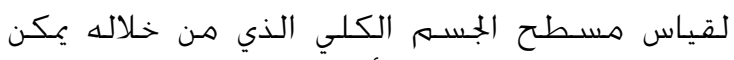

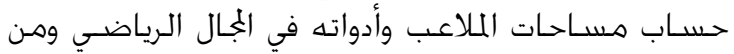

Formulas for Body Surface A rea :

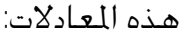

\section{The H osteller1 formula: 1}

3600)1/ 2] - BSA (m 2) $=(($ Height $(\mathrm{c} \mathrm{m}) \times$ Weight $(\mathrm{kg})$

$((\mathrm{cm} * \mathrm{~kg}) / 3600$

\section{The Dubois2 and Dubois formula}

Height $(\mathrm{m}) 0.725 X$ Wight $(\mathrm{kg}) . X *$ BSA $(\mathrm{m} \mathrm{2})=0.20247$ $X$ Height(c

* BSA $(\mathrm{m} 2)=0.007184 \times$ Height $(\mathrm{c}$ m) $0.725 \times$ Weight $(\mathrm{kg})$.

\section{The Haycock 3 formula}

- BSA $(m$ 2) $=0.024265 X$ Height(c m) $0.3964 \times$ Weight (kg) 0.5378

\section{The Gehan and G eorge4 formula 4}

- BSA $(m$ 2) $=0.0235 \times$ Height(c m)0.42246 X Weight $(\mathrm{kg}) 0.51456$

\section{The Boyd formula 5}

- BSA $(\mathrm{m} \mathrm{2})=0.0003207 \times$ Weight $(\mathrm{kg}) 0.3 \times$ Weight (grams) (0.7285)

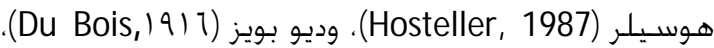

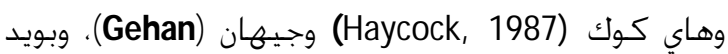

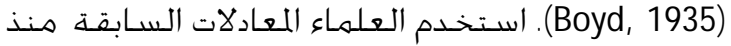

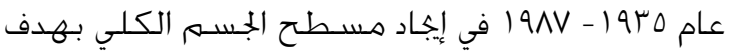

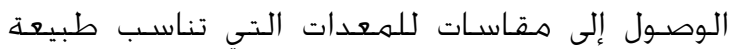

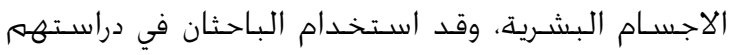

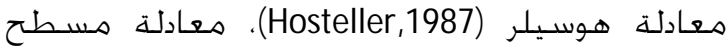

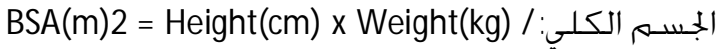
$3600) 1 / 2((\mathrm{~cm} * \mathrm{~kg}) / 3600)$

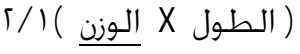

$$
\begin{aligned}
& \text { r. . }
\end{aligned}
$$

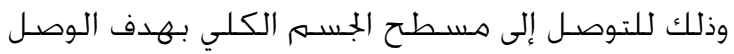

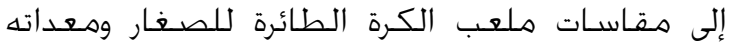

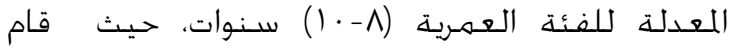

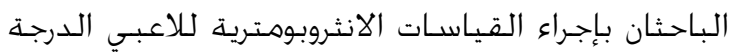

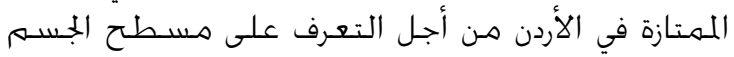

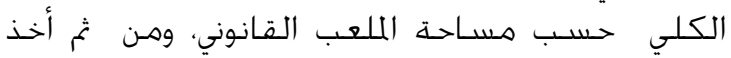

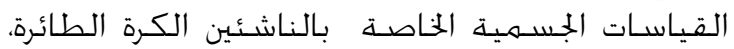
وعن طريق تطبيق مفهوم علم الهندسـة البشـرية ثم تم

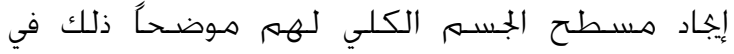

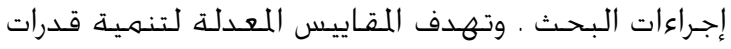

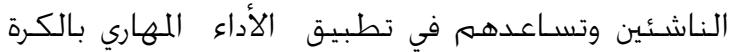

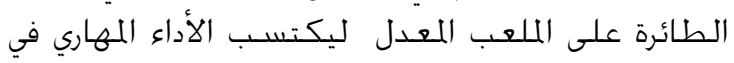

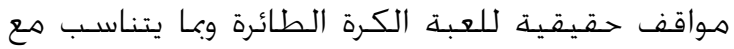

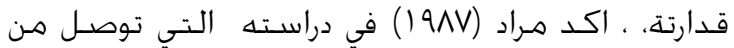

ارتبط تطبيق مفهوم علم الهندسـة البشـرية بالعلوم

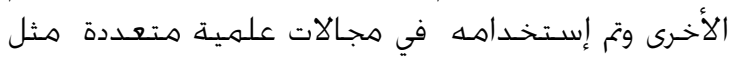

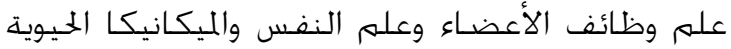

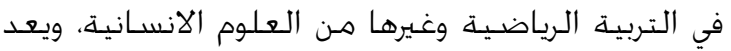

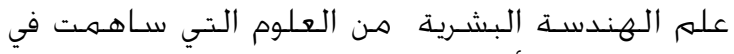

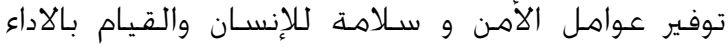

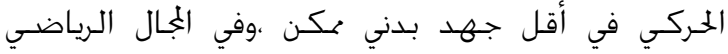

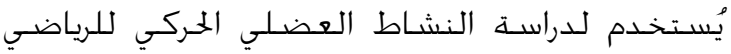

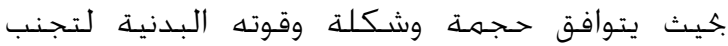

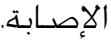

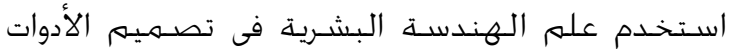

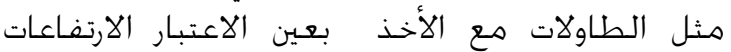

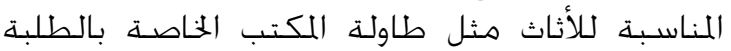

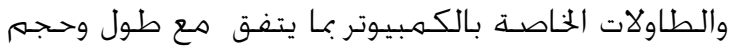

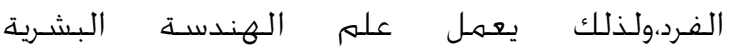
(الارجهونوميكس ) على تطبيق المعلوهات لتصـميـم مكان

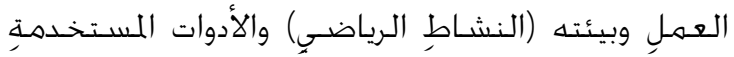
تبعا لطبيعة النشاط ومحدداته بهدف توفير عواهل

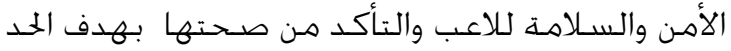

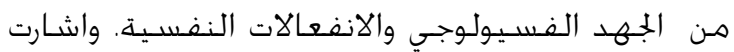

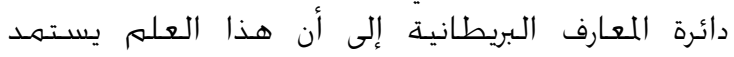

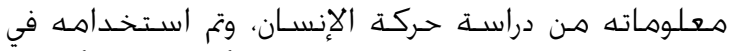

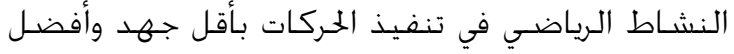

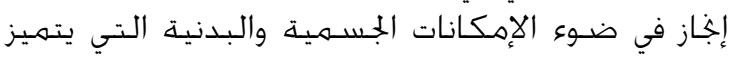

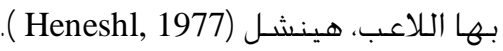

ويؤكـد عـمر (999 () بأن التربية الرياضـية ترتبط بالعلوم

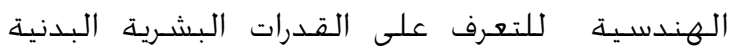

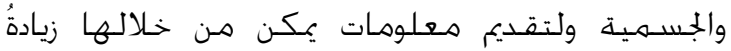

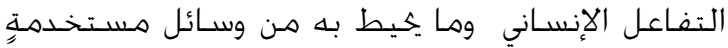

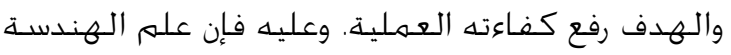

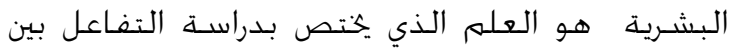

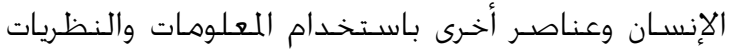

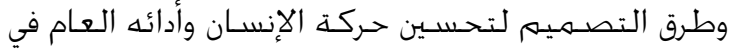

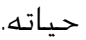

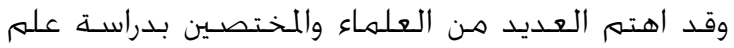

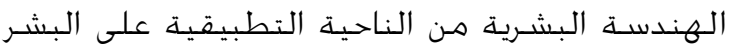

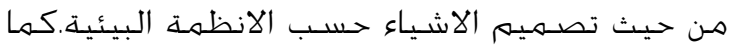

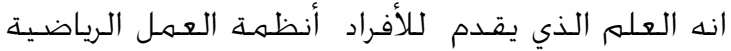

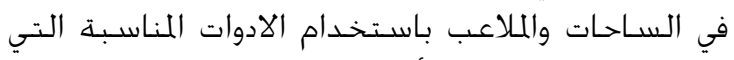

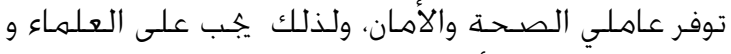

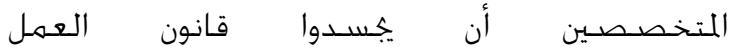

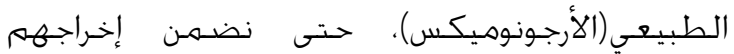

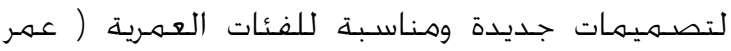

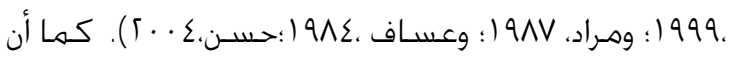

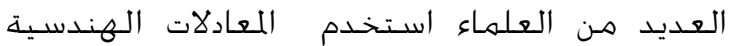




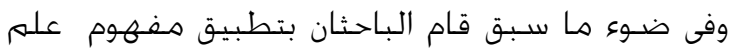

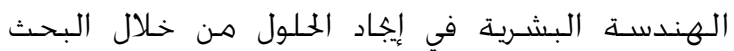

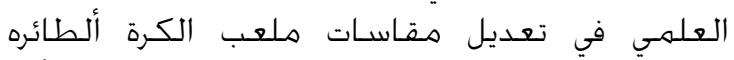
وهعداته بتطبيق مفهروم علم الهندسـة البشـرية، وأثره

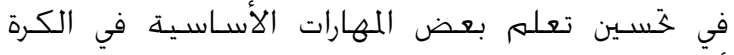

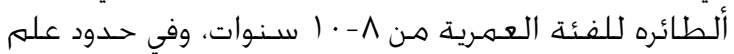

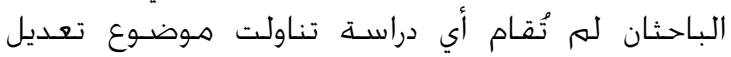

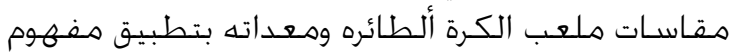

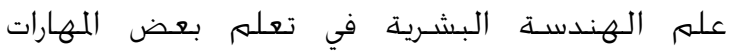
الأسـاسـية بالكرة ألطائره للناشـئين.

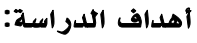

هدفت الــراسـة إلى التعرف على:

- أثر تعديل مقاسـات ملعب الكرة الطائرة

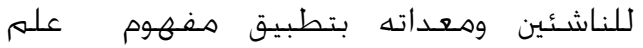

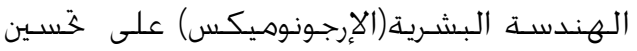
ألأداء المهاري بالكرة الطائرة.

- أثر مقاسـات ملعب الكرة الطائرة القـانوني للكرة

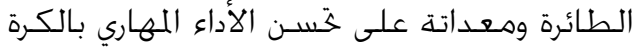
الطائرة للنـاشـئين.

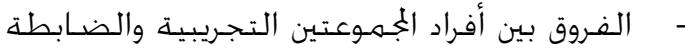
في خَسـين ألأداء المهاري بالكرة الطائرة للنـاشـئين.

\section{فروض الدراسة:}

- توجـد فـروق دالة إحصـائية عند مسـوى الدلالة ه ه.,.

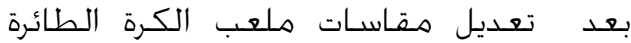

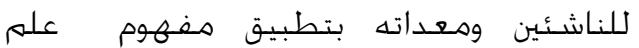

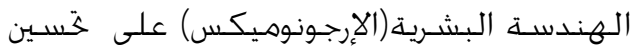

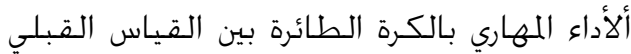

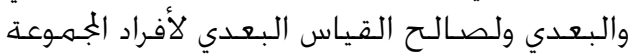

$$
\text { التجريبيـة. }
$$

- توجـد فروق دالة إحصـائية عند مسـتوى الدلالة

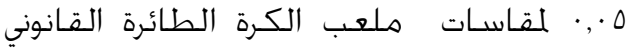

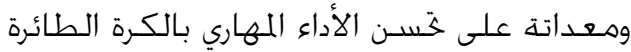

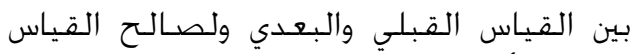

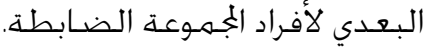

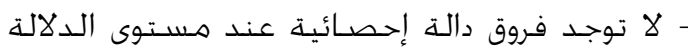

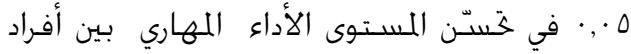
الجُموعتين التجريبية والضـابطة بالكرة الطائرة.

\section{محددات الدراسة:}

- الجمال البشـري: طلاب مدرسـة الفرير للفئة العهمرية

$$
\text { ^ - - ال سـنوات. }
$$

- الجُال الزهاني: تم تطبيق الــراسـة في الفــرة الواقعـة مـا

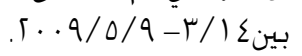

خلالها إلي مقاييس خـاصـة بملعب كرة اليد المصغرة.

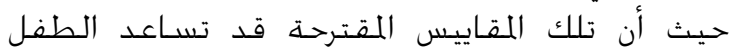

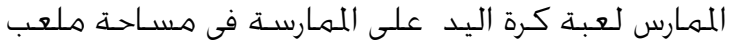

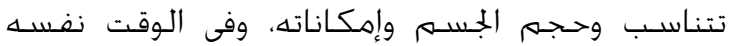

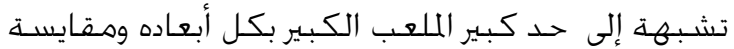

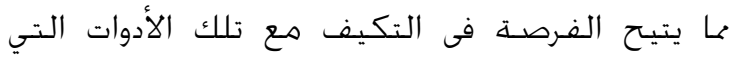

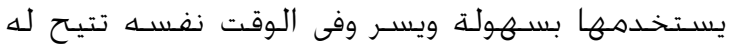

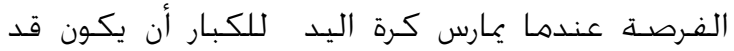

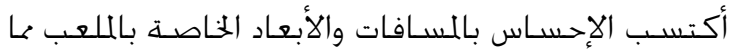

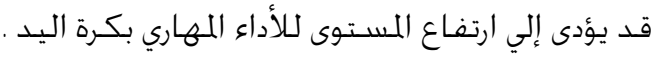
الكرة الطائرة نشـاط بدني يحتاج إلى قدرة وكفـاءة وتوافق

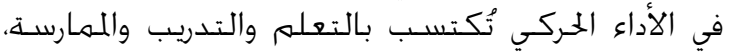

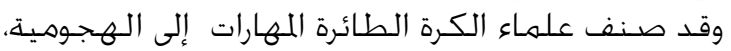

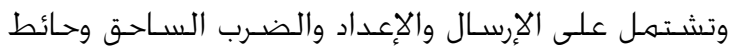

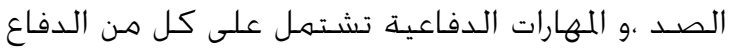

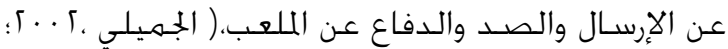
والخطايبه ، Fraser , 19M1 (1991 ).

وتظهر أهـمية الدراسـة في الاسـتجابة إلى ما نادى إلية

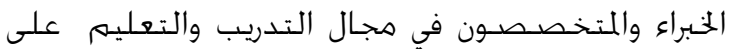

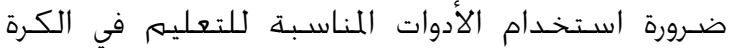

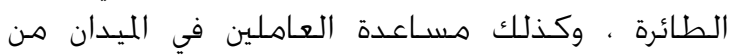

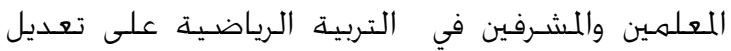

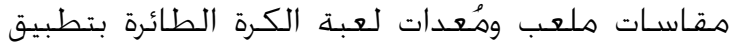

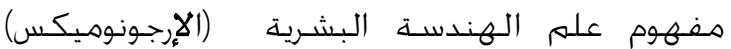

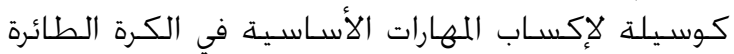

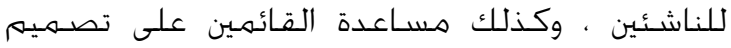

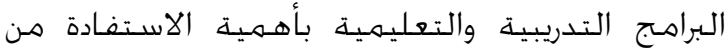

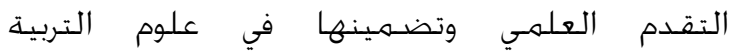

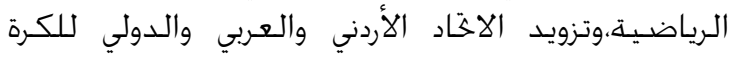

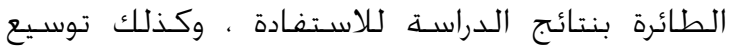

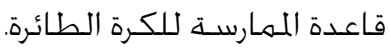

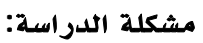

تطرق الاخّاد الدولي إلى قانون الكـرة الطائرة للكبار وترك

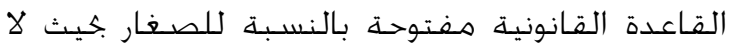

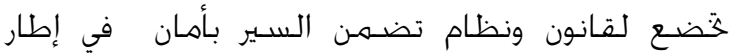

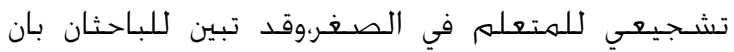

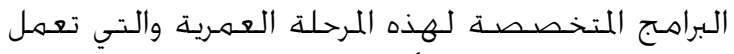

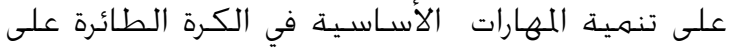

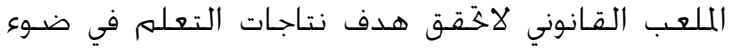

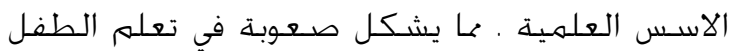

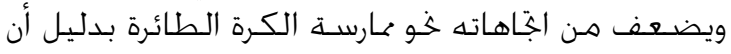

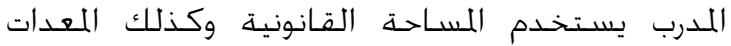

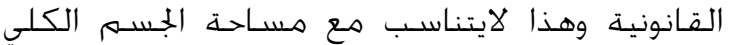
للمتعلم في هذه المرحلة العمـرية. 
وجُريبية حبث تلقت الجمهوعة التجريبية تدريبات لمدة سـت

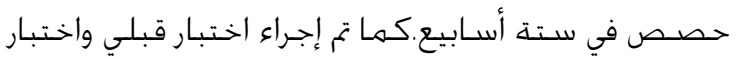

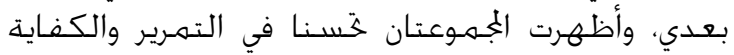

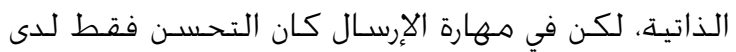

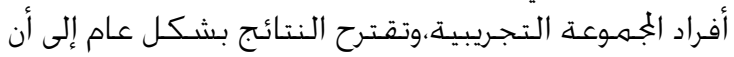

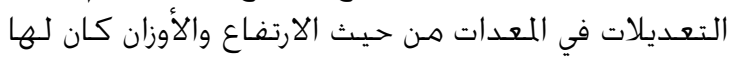

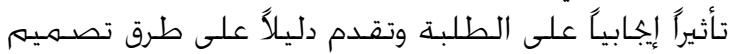

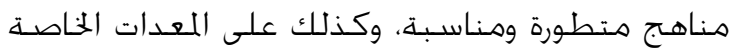
بالكرة الطائرة للطلاب.

دراسـة جورجيف (Georgieff, 2007) هدفت للتعرف إلى إلى إنائ

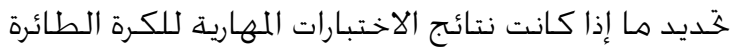

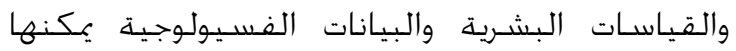

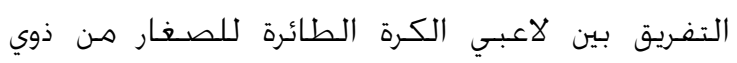

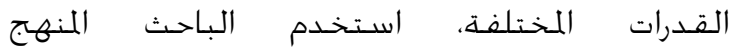

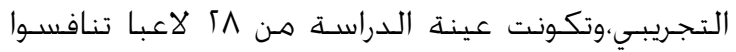

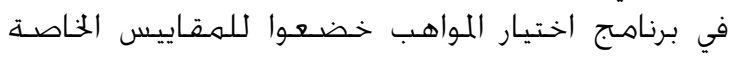

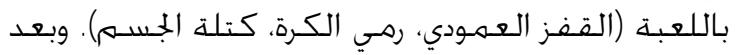

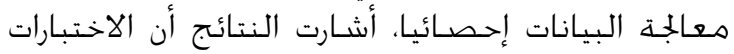

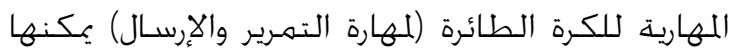

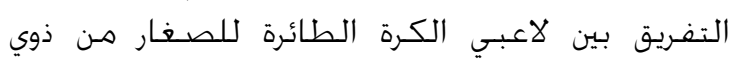

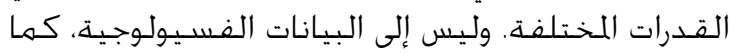

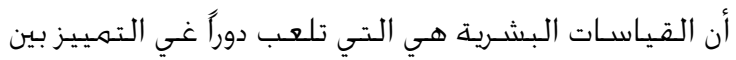

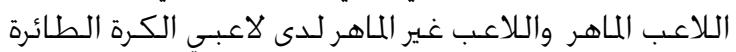

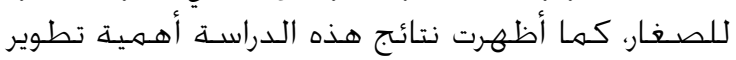
مهارتي التمرير والإرسال في لعبة الكرة الطائحة الكرائرة

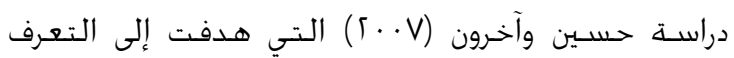

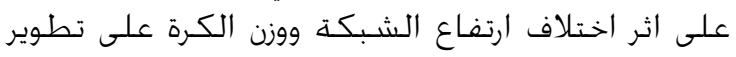

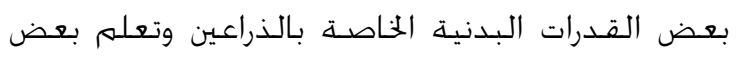

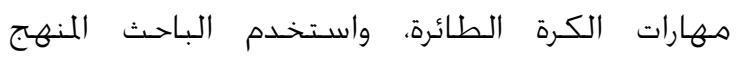

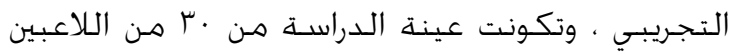

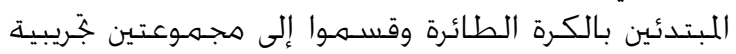

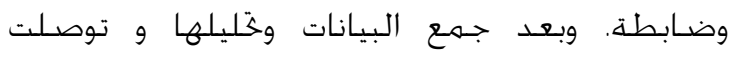

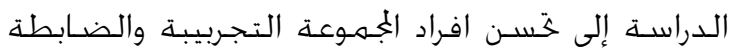

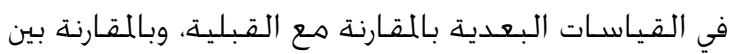

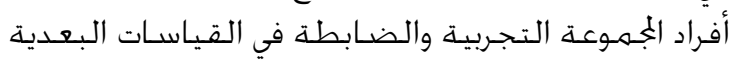
تشير النتائج لصالـح افراد الجمهوعة التجريبية.

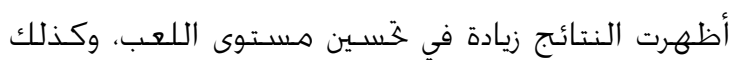

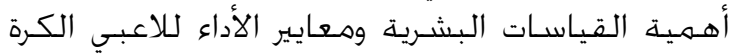

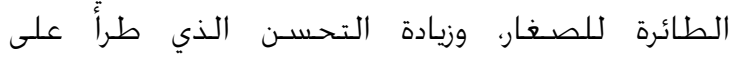

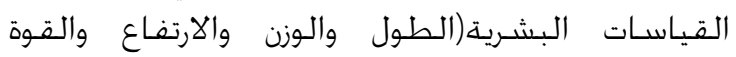

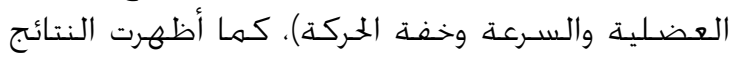

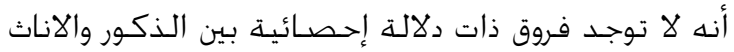
في وضع معايير للاداء الخاص في لعبة الكرة الطائرة.

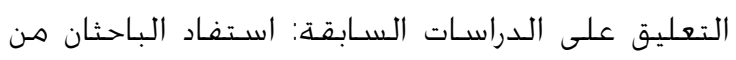

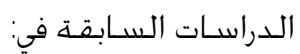

- الجُال المكاني: الملاعب والسـاحات في مدرسـة الفرير الخاصة في محافظة العاصمة.

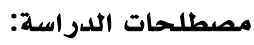

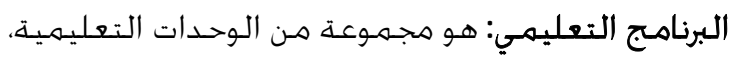

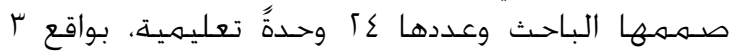

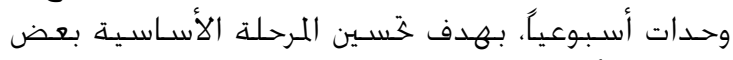

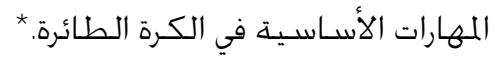

الملعب المعدل في الكرة الطائرة : هي المساحة (الملعب)

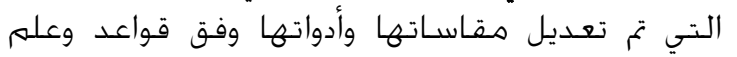

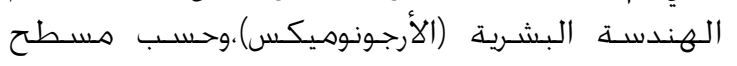

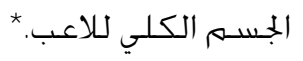

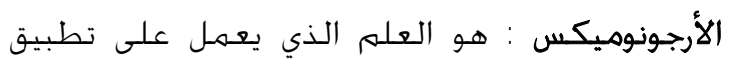

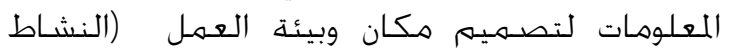

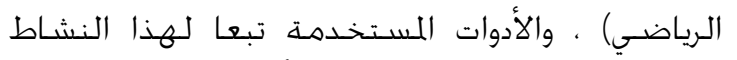

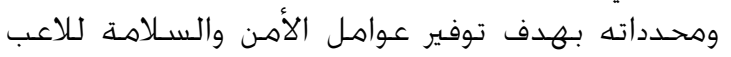

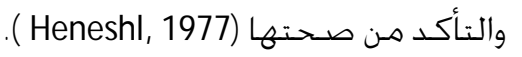

الدر اسات السابقة:

دراسـة مراد (9AV () ) هدفت للتعرف إلى المقاييس الجسـمية

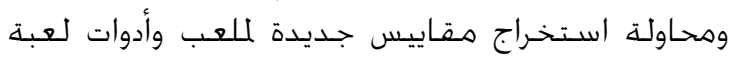

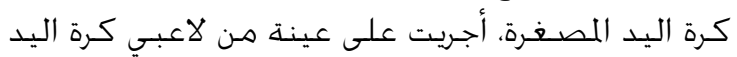

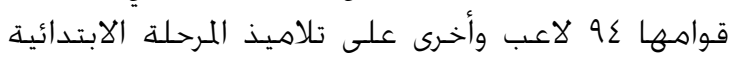

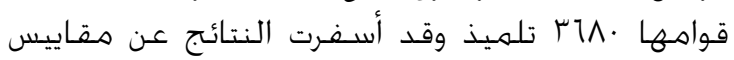

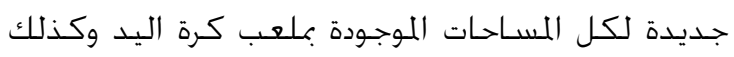
الأدوات المستخدمة في المباريات.

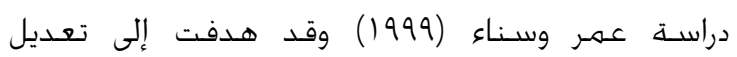

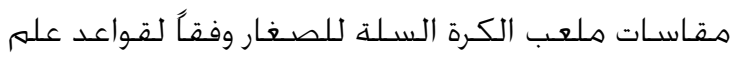

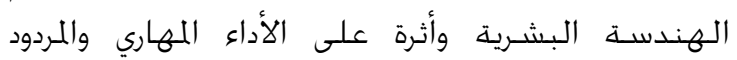

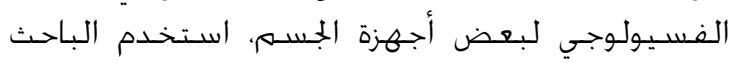

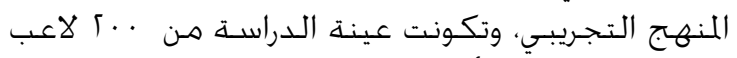

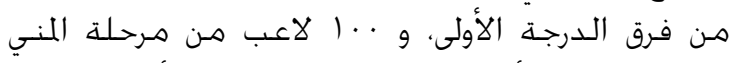

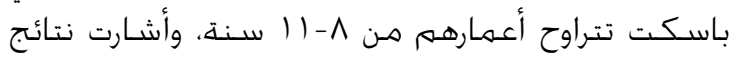

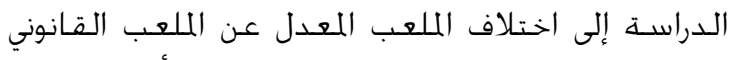

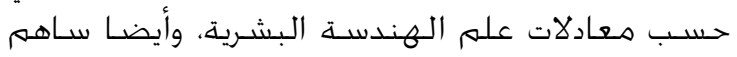

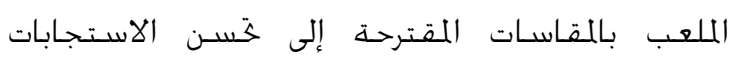

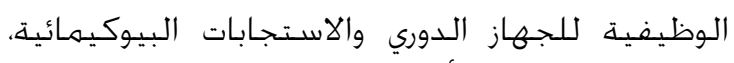

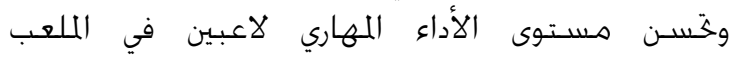
للمقاسـات المقترحة عن الملعب الحالي.

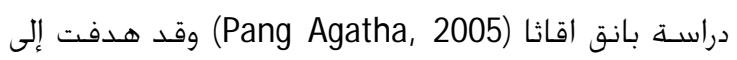

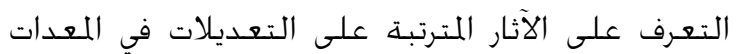

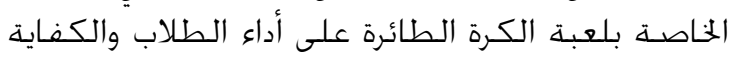

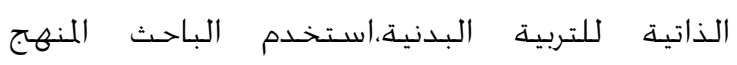

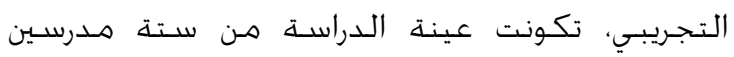

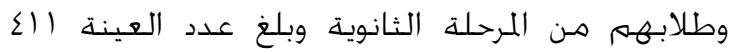

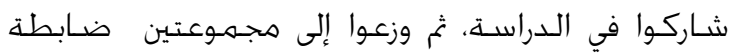




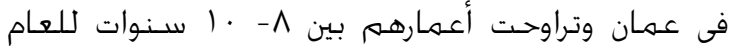

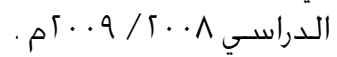
عينة الدراسـة: تم اختيار عينة الدراسـة بالطريقـة

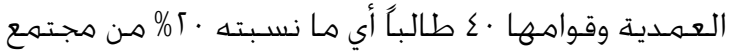

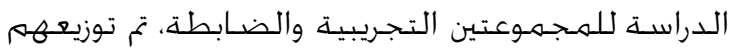

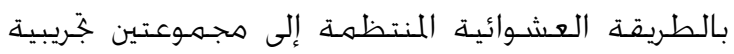

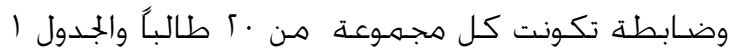
يبن مـواصـفات أفراد عينة الدراسـة. مجهـة

\section{التكافؤ بين الجُموعتين:}

أولاً: القياسـات الجسـمية: للتأكد هـن تكافؤ بيين أفراد

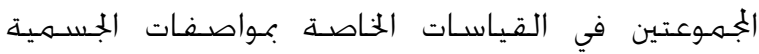
(الطول والوزن) استخــدم الباحثان المتوسـطات الحسـابية

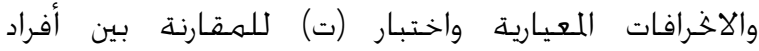

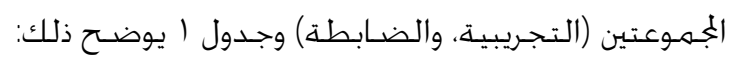

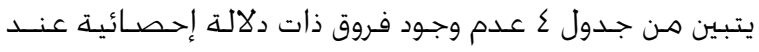

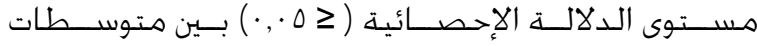

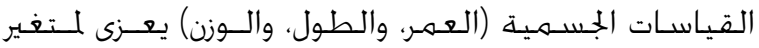

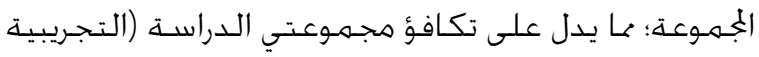

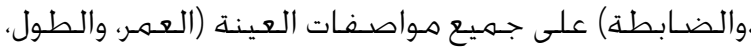

والوزن).

ثانياً:القدرات البدنية: تم اسـتخـدام المتوسـطات الخسـابية

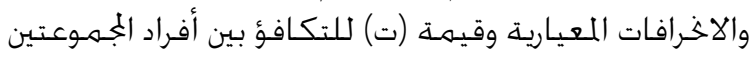

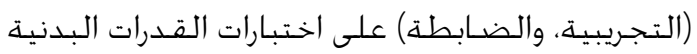

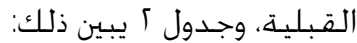

- - الاطلاع على الجمالات التي يتم فيها تعديل

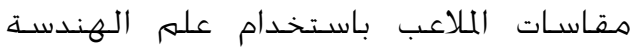

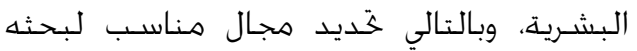
ودراستـه.

الاطلاع على التصـاميم التجريبية المستخـدمة بهرف ختديد التصـميهم الذي يناسـب دراستـه. - - اعتماد المنهج التجريبي للقياس القبلي والبعدي. - التوصل إلى اختيـار عينـة مـناسـبـة.

- - الحصـول على الأفكار المسـاعدة في تفسير النتائج

وتوضيحها.

- -

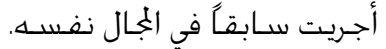

- القدرة على تصسميم البرنامج التعليمي على اجلى ل أسسس علميـة. - مسـاعدة الباحث في مناقشـة نتائج دراســه.

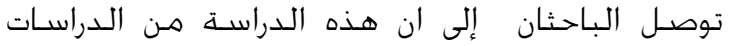

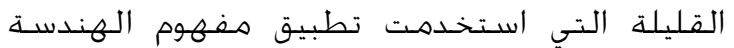
البشـرية في تعديل مقاسـات ملعب الكـرة الطائرة.

\section{الطريقة و الإجراءات}

استخـدم الباحث المنهج التجريبي بوصفـه المنهـج المناسـب لطبيعة هذه الدراسـة.

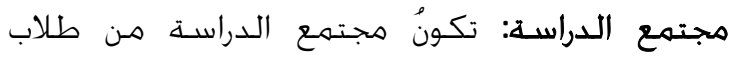

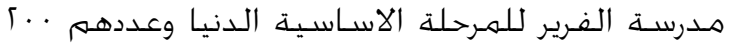

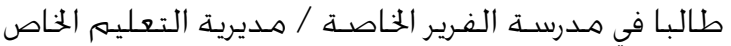
المتوسطات الحسابية والانحرافات المعيارية واختبار (ت) للتكافؤ في العمر والطول والوزن، لأفراد المجموعتين: التجريبية والضابطة

\begin{tabular}{|c|c|c|c|c|c|c|c|c|c|}
\hline الدلالة الإحصائية & درجة الحرية & قيمة ت & \multicolumn{2}{|c|}{ الانحر اف المعياري } & \multicolumn{2}{|c|}{ المتوسط الحساب } & \multicolumn{3}{|r|}{ مو اصفات العينة } \\
\hline \multirow[t]{2}{*}{$\cdot, \leqslant 09$} & \multirow[t]{2}{*}{$r \Lambda$} & \multirow{2}{*}{$\cdot, \mathrm{v} \leqslant 9$} & & $\cdot, \wedge 1$ & \multicolumn{2}{|r|}{9,40} & $r$. & تجريبية & \multirow[t]{2}{*}{ العمر (سنة) } \\
\hline & & & & $\cdot, \wedge \wedge$ & & 9,10 & $r \cdot$ & ضابطة & \\
\hline \multirow[t]{2}{*}{$\cdot, r r$} & \multirow[t]{2}{*}{ rᄉ } & \multirow[t]{2}{*}{$1, \cdots$} & & $V, V Y$ & \multicolumn{2}{|c|}{$1 \leqslant r, 70$} & $r \cdot$ & تجريبية & \multirow{2}{*}{ الطول (سم) } \\
\hline & & & & $9,0$. & & 1 १ , १. & $r$. & ضابطة & \\
\hline \multirow[t]{2}{*}{$\cdot, Y \backslash \vee$} & \multirow[t]{2}{*}{ rᄉ } & \multirow{2}{*}{$\cdot, r 70$} & & $V, V Y$ & & $r v, O$. & $r \cdot$ & تجريبية & \multirow[t]{2}{*}{ 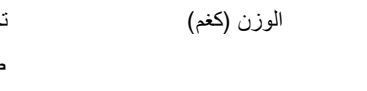 } \\
\hline & & & & $\mathrm{V}, \wedge \mathrm{T}$ & & $r ч, 7$. & $r$. & ضابطة & \\
\hline \multicolumn{10}{|c|}{ 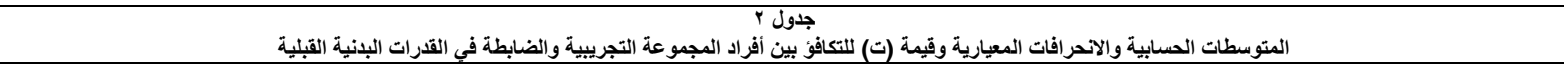 } \\
\hline الدلالة الإحصائية & درجة الحرية & قيمة ت & الانحراف المعياري & المتوسط الحسابي & ن & المجموعة & وحدات القياس & & الاختبار البدني \\
\hline \multirow[t]{2}{*}{$\cdot,+77$} & \multirow[t]{2}{*}{ rᄉ } & \multirow[t]{2}{*}{$1, \wedge 9$} & $0,0 \mathrm{~V}$ & $1 \%, 10$ & $r \cdot$ & تجريبية & \multirow[t]{2}{*}{$\doteq$} & \multirow{2}{*}{\multicolumn{2}{|c|}{ ثي الذراعين ومدهما لمدة · ب ث }} \\
\hline & & & $\varepsilon, \vee \wedge$ & $1 \cdot, 100$ & r. & ضابطة & & & \\
\hline \multirow[t]{2}{*}{$\cdot, v \cdot r$} & \multirow[t]{2}{*}{ ru } & \multirow[t]{2}{*}{$\cdot, \Gamma \wedge \varepsilon$} & r, §1 & $1 \Lambda, r$ & r. & تجريبية & $\dot{ث}$ & & الجلوس من الرقود لمدة •r ث \\
\hline & & & $r, i v$ & $1 \wedge, 7$ & r. & ضابطة & & & \\
\hline$\cdot, \times)$. & ru & , rVo & $\cdot, r q$ & 7,90 & r. & تجريبية & $ث$ & & السرعة (10م) بعرض الملعب من البدء العالي \\
\hline & & & $\cdot, \leqslant 0$ & 7,9 . & r. & 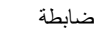 & & & \\
\hline$\cdot, r \ldots$ & ri & $1, .01$ & $|r, 7|$ & $1 \leqslant V, r_{0}$ & r. & 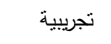 & سم & & الوثب الطويل من الثبات \\
\hline & & & $9,1 r$ & $1 \leqslant r, \leqslant$. & r. & ضابطة ابط & & & \\
\hline$\cdot, 190$ & ri & $1, r r)$ & $1 \cdot, \lambda r$ & $r \cdot r, 00$ & r. & 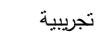 & سم & & الوثب العمودي للأعلى \\
\hline & & & $\wedge, \S 1$ & $199,0$. & $r \cdot$ & ضابطة ابط & & & \\
\hline$\cdot, \wedge$. & rᄉ & $1, \wedge \cdot 1$ & $\cdot, 99$ & 0,9 . & r. & تجريبية & سم & & رمي كرة طبية اكغم باليدين من خلف الرأس \\
\hline & & & $\cdot, 90$ & $0, r \leqslant$ & r. & ضابطة ابط & & & \\
\hline$\cdot, Y \wedge \vee$ & rی & $1, \cdot 19$ & $\varepsilon, \wedge \vee$ & $r V, \leqslant V$ & r. & تجريبية & كغ & & قوة القبضة \\
\hline & & & $\varepsilon, 1 \Gamma$ & ro, 9 r & $r \cdot$ & ضابطة ابط & & & \\
\hline
\end{tabular}


-استـمارة المعلومات والبيانات للعينة. -ملعب كرة طائرة قانوني . -ملعب كرة طائرة معدل.

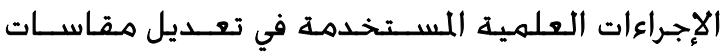
ملعب الكرة الطائرة ومعداتة للناشئين:

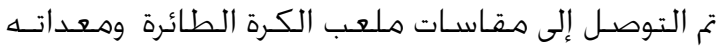

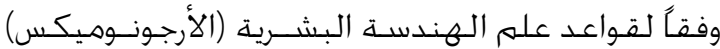

وهـن خلال تطبيق معادلة هوسـتلر (Hosteller,1987).

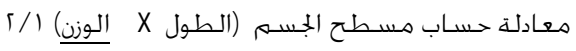
rา.

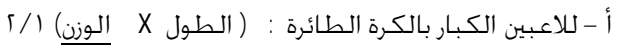

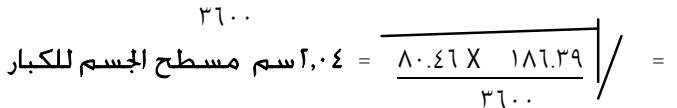

ب - للناشئين الكرة الطائرة : - ( الطول X الوزن ) (/ X r..

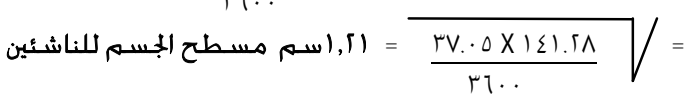

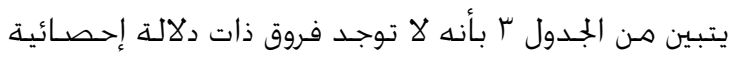

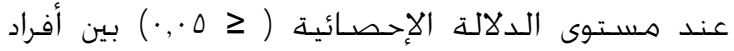

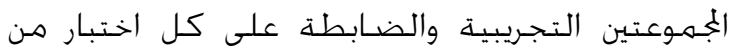

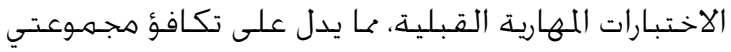

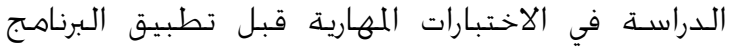

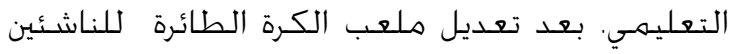
وهعداته بتطبيق مفهوم علم الهندسـة البشـية (الارجـونوهيكس).

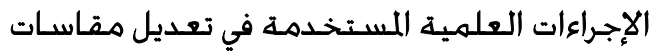

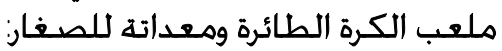

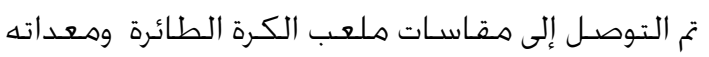

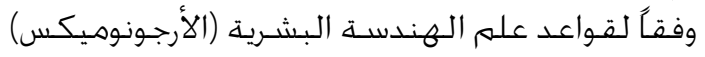
وهمن خلال المعادلة التالية (Hosteller,1987):

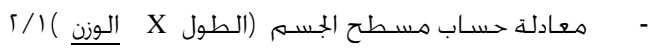

يتبين مـن جـدول 「 بأنه لا توجـد فروق ذات دلالة إحصائية

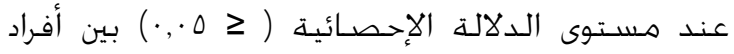

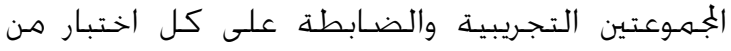

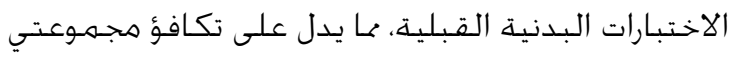

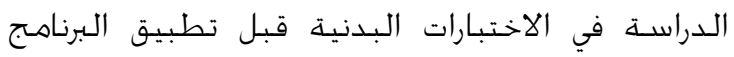

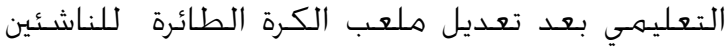

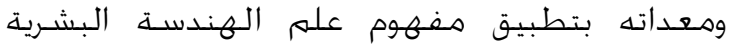
(الارجـونوهيكس). ب) الجـزء الثاني: الاختبـارات المهارية القبلية: تم استخـدام المتوسـطات الخسابية والاخـرافات المعيارية

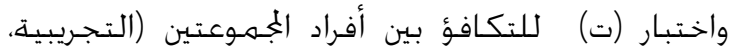

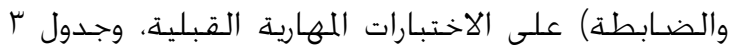
يبين ذلك:

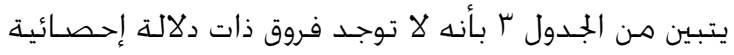

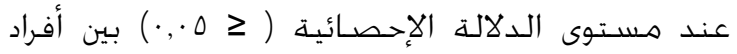

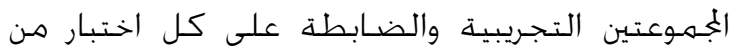

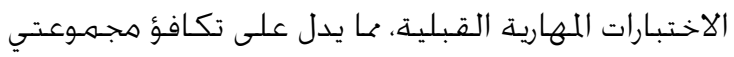

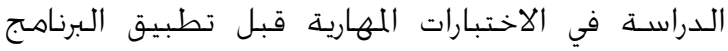

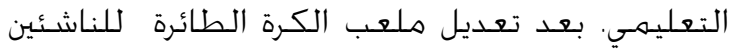

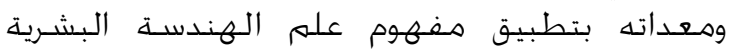
(الارجـونوهيكس).

\section{الأدوات والأجهزة المسـخـدمة في الدراسـة:}

-جهاز الرستاميتر لقياس الطول والوزن.

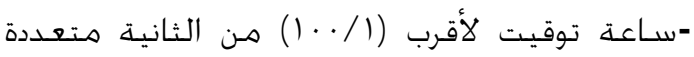
الأغراض.

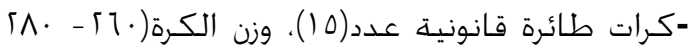
غرام) بمسحيط (10-10 ستسم).

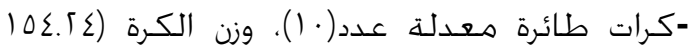

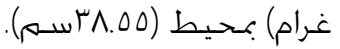

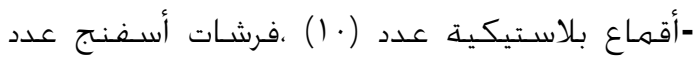
1 ، شريط قياس، شـريط لاصـق وطبـاشـير.

جدول r - (

التكافؤ بين أفراد المجموعتين في مستوى الأداء المهاري في القياسات القبلية

\begin{tabular}{|c|c|c|c|c|c|c|c|c|}
\hline الدلالة الد & الحرية & قيمة ت & المعياري & الحسابي & ن & المجموعة & وحدة & الاختبار البدني \\
\hline \multirow{2}{*}{ r, sor } & ru & $\cdot$, У०१- & $r, r r$ & $r, \wedge$. & $r \cdot$ & تجريبية & | درجة * & إرسال من أسفل أمامي مواجه \\
\hline & & & i,rt & r, ro & r. & ضابطة & & \\
\hline \multirow[t]{2}{*}{$\cdot, 7 \wedge 1$} & rs & $\cdot, \varepsilon \cdot 0$. & $1, r 9$ & $\cdot, 90$ & r. & تجريبية & | درجة * & إرسال من أعلى التنس \\
\hline & & & $\cdot, \wedge 9$ & $\cdot, \wedge$ & r. & ضابطة & & \\
\hline \multirow[t]{2}{*}{$\cdot, 0 \vee 0$} & rs & .074 & $1, r 9$ & $\cdot, 00$ & r. & تجريبية & درجة * & الإعداد العالي لمركز ؛ \\
\hline & & & $\cdot$, Vo & , ro & $r \cdot$ & ضابطة & & \\
\hline \multirow[t]{2}{*}{ • } & rᄉ & $1, \cdot r \leq$ & •, r & $\cdot, .0$ & $r \cdot$ & تجريبية & درجة * & استقبال الإرسال \\
\hline & & & ז & $\cdot, r \cdot$ & r. & ضابطة & & \\
\hline \multirow[t]{2}{*}{$\cdot, 197$} & rs & l, riv- & $1, \wedge \wedge 1$ & $r, \varepsilon \cdot$ & $r$. & تجريبية & درجة & ضرب ساحق مستقيم \\
\hline & & & 1,17 & 1, Vo & $r$. & ضابطة & & \\
\hline
\end{tabular}




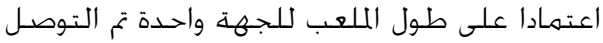

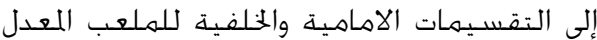
كما هو موضسح في الجدول ه

جدول

قياسات الملعب القانوني والمعدل

\begin{tabular}{|c|c|c|}
\hline قياسات الملعب & قياسات الملعب & الوصف \\
\hline المعدل ومعداته & القانوني ومعداته & \\
\hline$p^{1 r, q .}$ & 11 & الطول \\
\hline 7,90 & 9 & العرض \\
\hline \multirow[t]{2}{*}{ r r,r } & $r$ & المنطقة \\
\hline & & الأمامية \\
\hline rT & 1 & المنطقة الخلفية \\
\hline م & $r, \varepsilon r$ & ارتفاع الثبكة \\
\hline p & $1 \wedge$. & ارتفاع الهوائي \\
\hline P 1,9v & roo & طول القوائم \\
\hline$v, r \varepsilon$ & $9,0$. & طول الثبكة \\
\hline $10 \leqslant, Y \leqslant$ & . דr غم. & وزن الكرة \\
\hline r r,07 سم & 10 10 & محيط الكرة \\
\hline
\end{tabular}

الاختبارات المستخـدمة في الدراسـة:

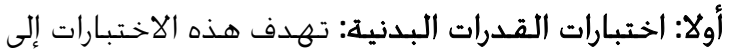

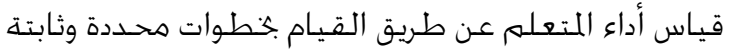

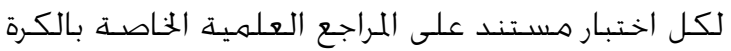

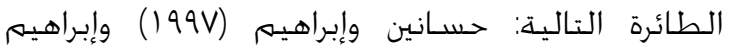

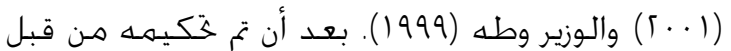

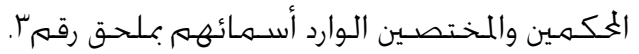

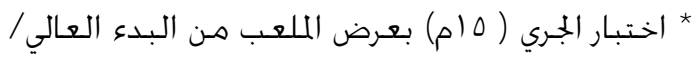
ث

* اختبار رهي كرة طبية ( الرغم ) باليدين من خلف

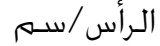

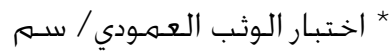

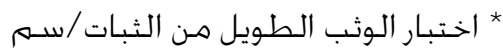

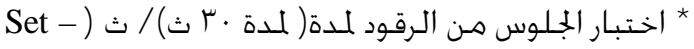

(Up * اختبار الدفع لأعلى أو الانبطاح المائل، ثني الذراعين

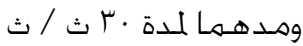

* اختبار قوة القبضة / كغم. جهاز الديناموهيتر

(Dynamometer)

ثانبا: اختبارات الأداء المهاري: عُرضت الاختبارات المهارية

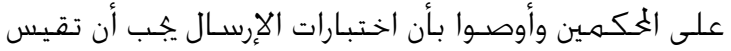

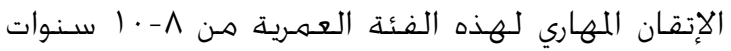

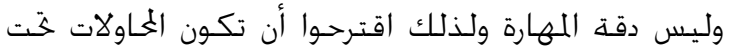

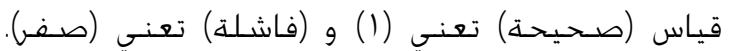
والملحق ع يوضح ذلك. * اختبار الإرسال من أسفـل أمامي مواجهة.

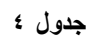

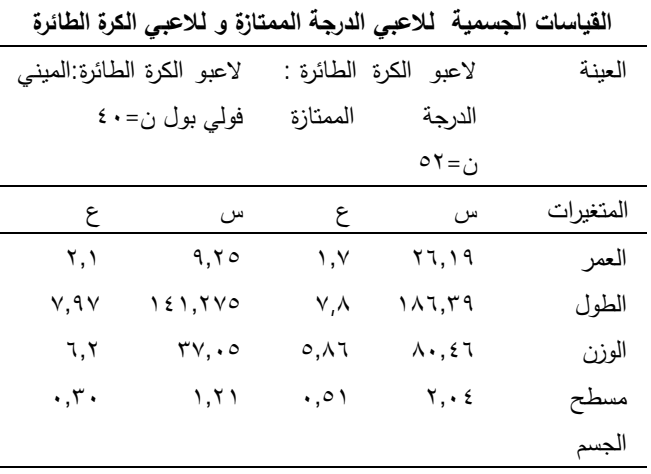

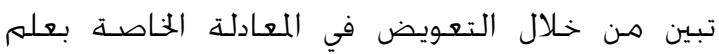

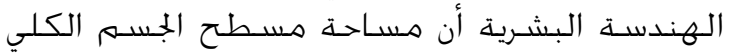

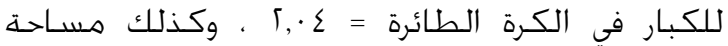

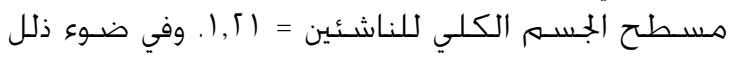
يمكن التعويض الجي المعادلة على النحو الاتي : مساحة مساحة الملعب الجسم للاعبي الكرة الطائرة الكبار

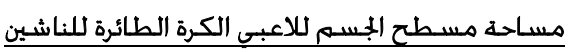

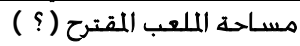

$$
\frac{1, \Gamma 1}{s}=\frac{\Gamma, \cdot \varepsilon}{17 r}
$$

? التقبريب

نسبة الطول إلى العرض في الملعب القانوني ا ـ ـا وبما أن الطول

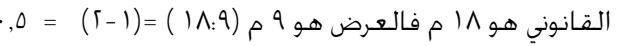

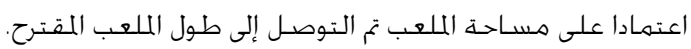

$$
\text { - }
$$

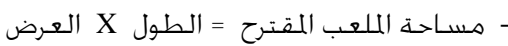

$$
\begin{aligned}
\cdot, \Delta X_{\omega} & =97,1 \\
., \Delta X_{\omega} & = \\
\Gamma_{\omega, 0} & =
\end{aligned}
$$

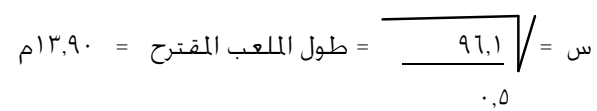

اعتماداً على طول الملعب المقترح تم التوصل إلى عرض

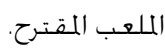

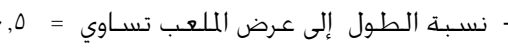

.

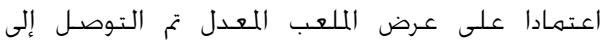

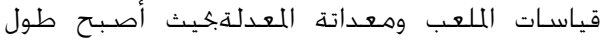

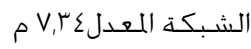

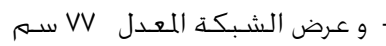

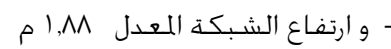

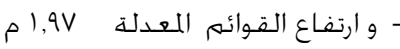

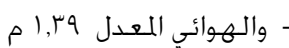




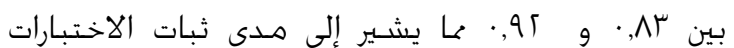

$$
\text { وصـلاحيتها للتطبيق. }
$$

يتضـح من جدول V أن اختبارات الأداء المهاري المستخدمدة

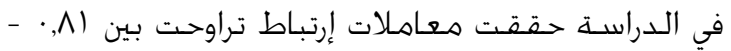

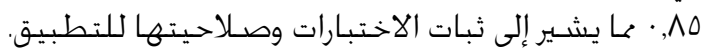

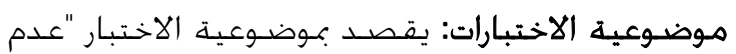

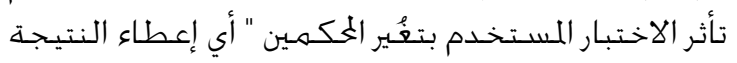

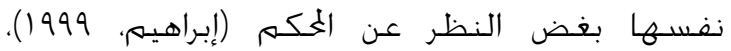

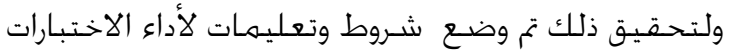

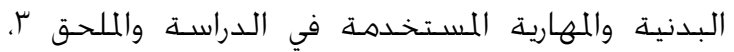

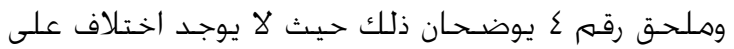

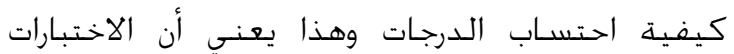

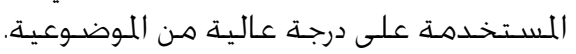

البرنامج التعليمي المقترح: قام الباحثان بإعداد البرناهـج

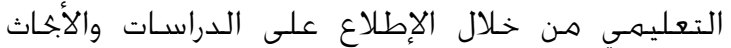

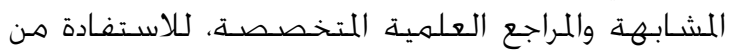
برامجها التعليمية ومهنها:

' ـ علم الهزندسـة البشرية(الأرجونوهيكس)، وجـور

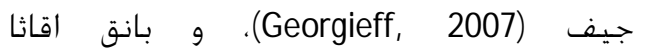

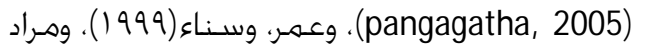

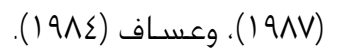
؟ - المهارات الأسـاسية في الكرة الطائرة، حسـين

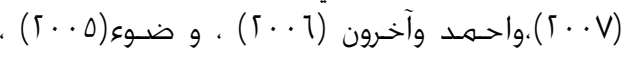

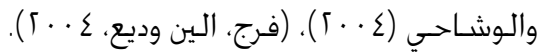

* اختبار الإرسـال مـن أعلى مواجهة (التنس). * اختبار دقـــــهـارة الاسـتقبـال في الكـرة الطائرة. * اختبار الإعداد.

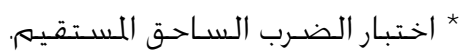

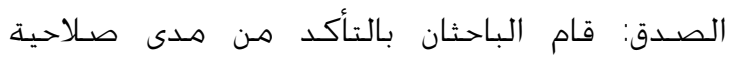

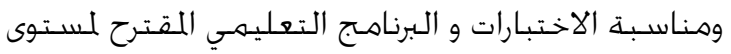

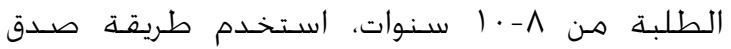

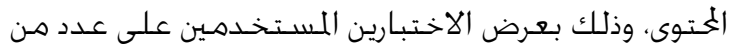

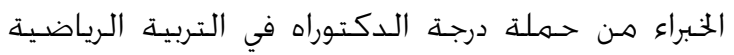

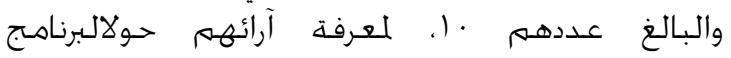

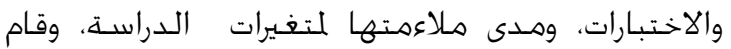

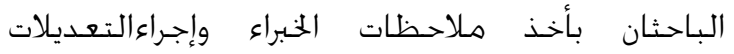

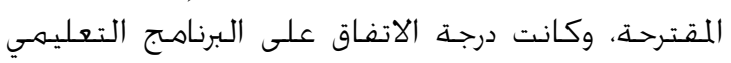

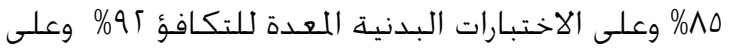

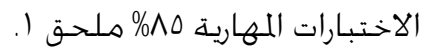

الثبات: تم التحقق هـن ثبات أداة الدراســـ هـن خـلال

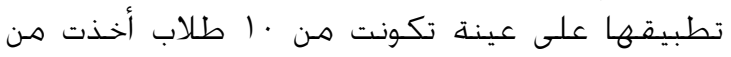

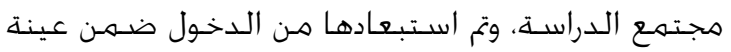
الدراسـة، وذلك بطريقـة الاختبار وإعادته، (Test-Retest)

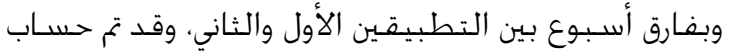

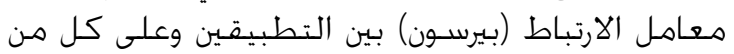

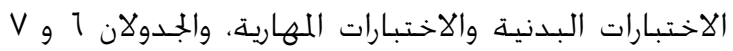
يوضحان ذلك. يتضح هن جدول 1 أن اختبارات اللياقة البدنية

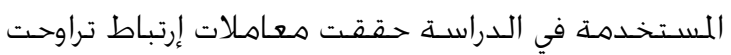

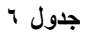

معامل ثبات الإعادة لكل اختبار من الاختبارات البننية

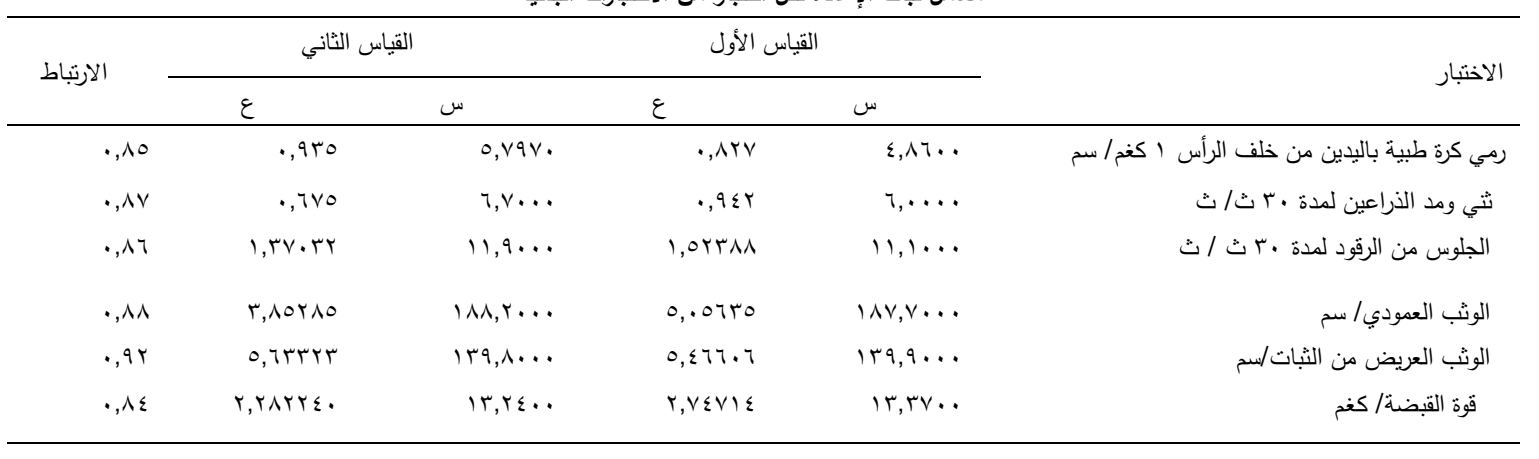

جدول

\begin{tabular}{|c|c|c|c|c|c|}
\hline \multirow{2}{*}{ معامل الثبات الإعادة } & \multicolumn{2}{|c|}{ القياس الثاني } & \multicolumn{2}{|c|}{ القياس الأول } & \multirow{2}{*}{ الاختبار } \\
\hline & $\varepsilon$ & س س & $\varepsilon$ & س س & \\
\hline$\cdot$, Ar & $\cdot, \vee \leq$. & 1,7 & $\cdot, V \leq$ & 1,9 & الإرسال من أسفل أمامي مواجه \\
\hline$\cdot, \lambda)$ & $\cdot, \wedge \wedge$ & $\cdot, 9$ & $\cdot, \times)$ & $\cdot, 0$ & الإرسال من أعلى (النتس) \\
\hline$\cdot, \lambda)$ & $\cdot, \wedge \leq \Gamma$ & $r, 7$ & $\cdot, 9 \leqslant \wedge$ & $1, v$ & استقبال الإرسال من أسفل \\
\hline 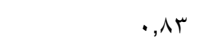 & ש & $r, r$. & $\cdot, \wedge / 7$ & $r, \ldots$ & الإعداد العالي لمركز ء \\
\hline$\cdot$, , & $\cdot, v \leq$. & 1,9 & $\cdot, 91 \wedge$ & $1, r$. & الضرب الساحق المستقيم \\
\hline
\end{tabular}

معامل ثبات الإعادة لكل اختبار من الاختبارات المهارية 
ז) الجزء الرئيسي: يحتوي على مجهوعة من التدريبات

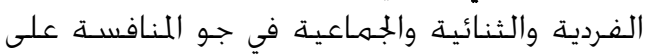

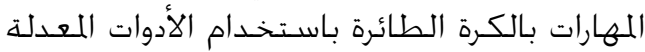

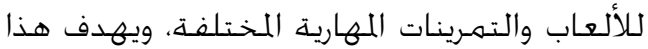

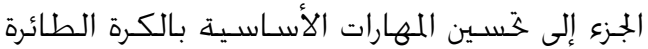

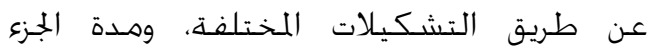

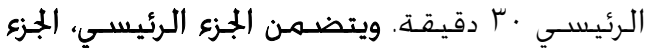

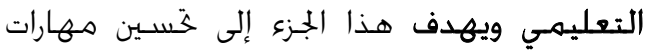

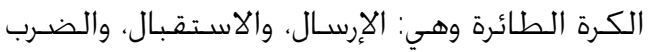

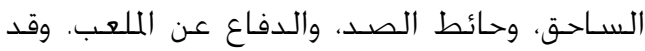

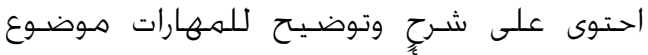

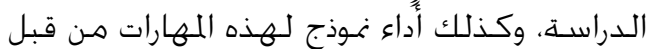

المعلم.

r) أما الجزء التطبيقي فيهدف إلى تطبيق مهارات

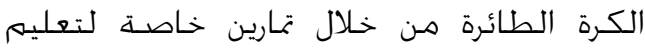

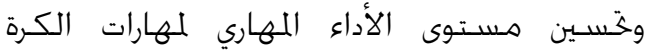

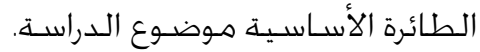

ع) الجزء الختامي: يهدف إلى تهدئة الجسـم والعودة الجهائ

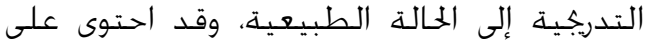

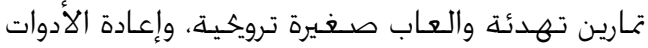

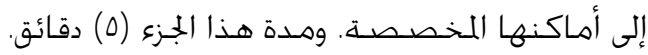
والللحق آيوضسح ذلك.

الدراسـة الاستطلاعية: تعد الدراسـة الاستطلاعية

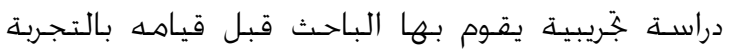

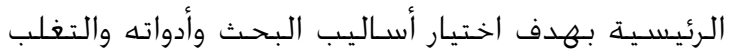

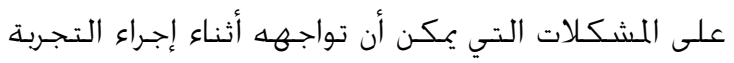

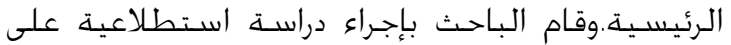

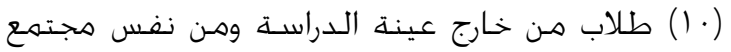

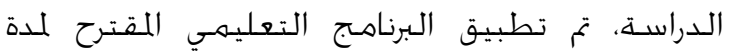

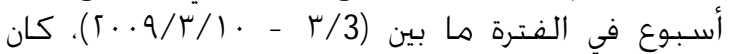

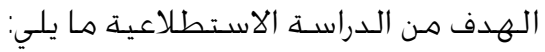

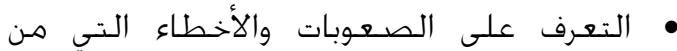
المهكـن أن تواجه الباحث أثناء التطبيق.

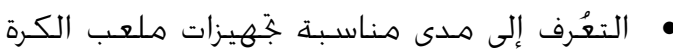

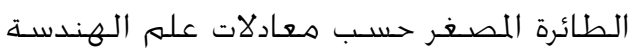
البشـرية.

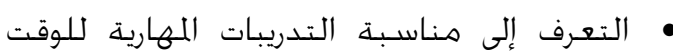
العـدد لـها، وتوزيع أجزاء الوحـدة التعليـيميـة.

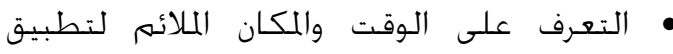
الـبرناهج.

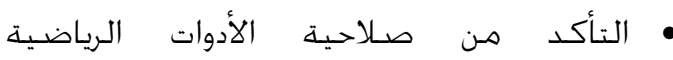
المسـتخـدمة في الدراســة وهدى توفـرها. ختديد الأسـلوب التنظيهـي للعهمل.
وصـف الـبرنامـج التعليمسي هـن حيث:

اولًا: المدة الزمنية للبرنامج التعليمي: زهـن الوحدة

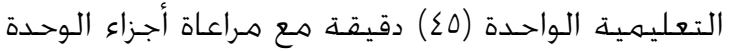

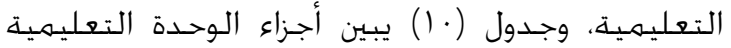

للبرنامهج اللقتـرح. ثانياً: أجزاء الوحسدة التعليمية:

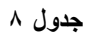

التوزيع الزمني لأجزاء الوحدة التعليمية للبرنامج المقترح

\begin{tabular}{|c|c|}
\hline الزمن في الوحدة اليومية بالدقائق & أجزاء الوحدة \\
\hline 1. & الجزء التمهيدي \\
\hline r. & الجزءالرئيسي \\
\hline 。 & الجزء الختامي \\
\hline$\leq 0$ & المجموع \\
\hline
\end{tabular}

ثالثاً:أهداف البرنامج التعليمي المقترح'

يهدف البرنامهج لتحسين الأداء اللهاري بالكـرة الطائرة

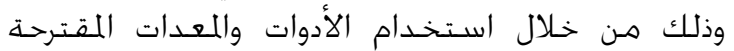
القائمهة على تعديل مقاسـات ملعب العب الكرة الطائرة

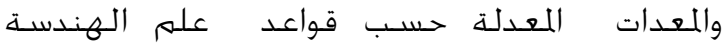
البشـرية (الأرجـونوميكس) على النـحو الآتي: -

- اسـتخـدام الملعب المصـر حسب معادلات الهزيدسـة

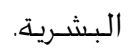

- استخــدام القياسـات والأدوات المعدلة في البرناهـج

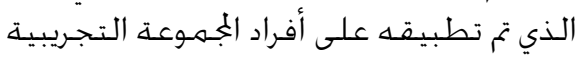

- تطبيق الأداء المهاري في الكـرة الطائرة وفقا

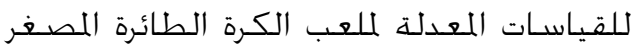

$$
\text { وحسـب قواعد علم الهـندسـة البشـرية. }
$$

- استخــام برنامج تعليهي لتنمية المهارات الأسـاسـيـة في الكـرة الطائرة.

- تدريبات فردية على المهارات بالكرة الطائرة

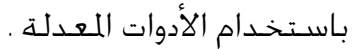

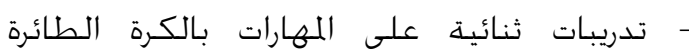

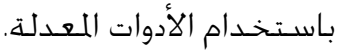
- تدريبات جـماعية على المهارات بالكرة الطائرة

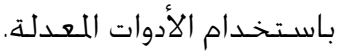
أجزاء الدرس: تم تقسيهم الوحدة التعليمية على النـحو التالي:

( ) الجزء التمهيدي: يهدف إلى تسـجيل الغياب، وتهيئة

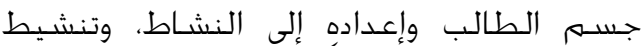

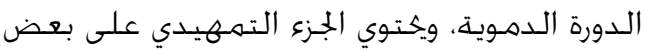

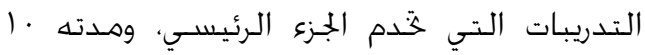


تصميم الدراسـة: المتغير المستقل: ملعب الكرة الطائرة المعدل بتطبيق مفهوم علم المهندسـة البشرية.

المتغير التابع: مهارات الكرة الطائرة على اللعب المعدل.

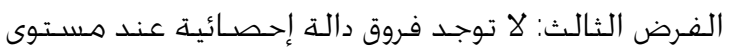

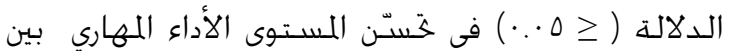
أفراد الجُموعتين التجريبية والضـابطة بالكرة الطائرة.

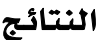

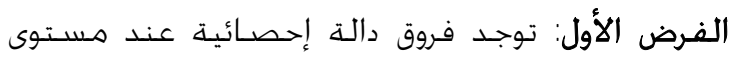

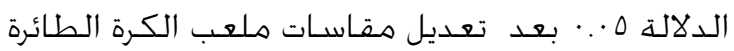

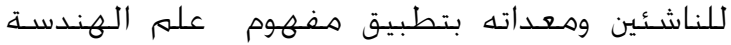

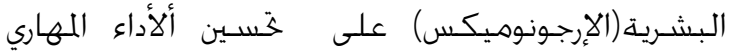

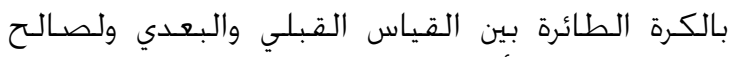
القياس البعدي لأفراد الجمهوعة التجريبية.

يشير جدول 9 إلى قيم المتوسطات الحسابية والاخرافات

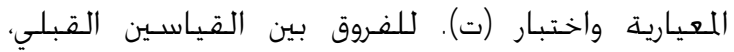

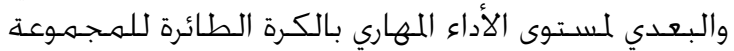

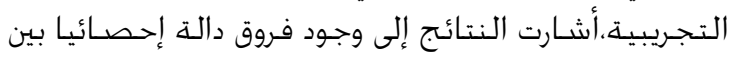

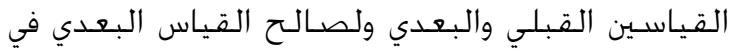

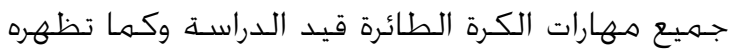

الدلالة الاحصائية في جدولهو الطيائوة.

$$
\begin{aligned}
& \text { • ختديد عدد الفـريق المسـاعد والوجبات التي } \\
& \text { استندت إليه. } \\
& \text { إيجاد المعاملات العملية للاختبارات. }
\end{aligned}
$$

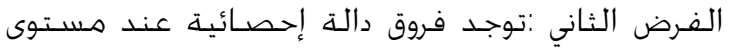

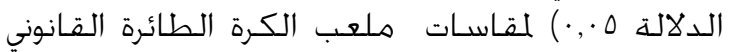

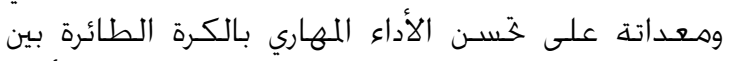

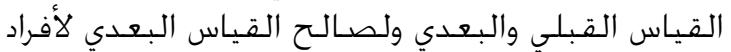

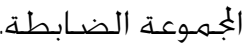

يشير جدول 9 إلى قيم المتوسطات الحسابية والاخرافات

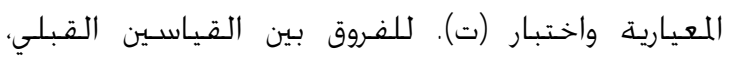

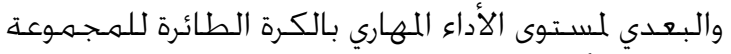

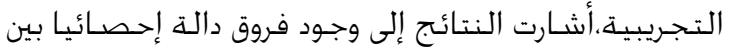

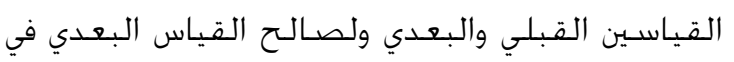

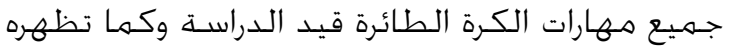

الدلالة الاحصـائية في جدوله

يتضح من جدول ·. قيم المتوسطات الحسابية والاخرافات اللعيارية وقيمة (ت). للفروق بين القياء القياسين

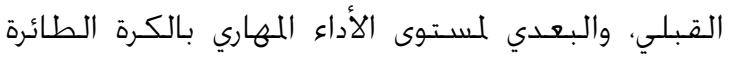

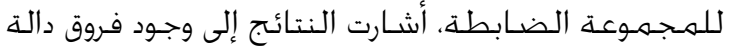

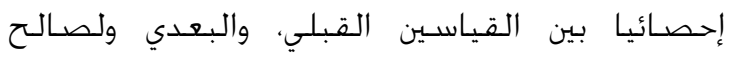

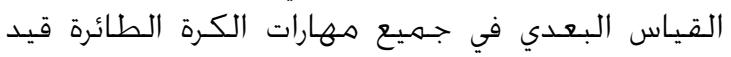

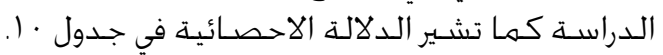

\begin{tabular}{|c|c|c|c|c|c|c|c|c|}
\hline دلالة إحصائية & درجة الحرية & ق قيمة ت & $\varepsilon$ & س & ن & القياس & وحدة القياس & المهارة \\
\hline \multirow{2}{*}{$\cdot, \cdots 1$} & 19 & $11, \varepsilon \leq 9$ & Tr, & $r, \wedge$. & r. & 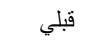 & درجة & الإرسال من أسفل أمامي مواجه \\
\hline & & & $r, 1 \varepsilon$ & $\wedge, \leqslant 0$ & $r \cdot$ & بعدي & & \\
\hline \multirow[t]{2}{*}{$\cdot, \cdots 1$} & 19 & $11, \varepsilon r_{0}$ & $1, r q$ & $\cdot, 90$ & r. & 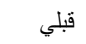 & | درجة & الإرسال من أعلى(النتس) \\
\hline & & & r,Ar & $V, \varepsilon 0$ & $r \cdot$ & بعدي & & \\
\hline \multirow[t]{2}{*}{$\cdot, \cdots 1$} & 19 & $\mid r, \leq 01$ & $1, r q$ & $\cdot, 00$ & $r \cdot$ & 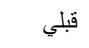 & 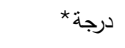 & الإعداد العالي لمركز ع \\
\hline & & & $r, 0 \leqslant$ & $v, 10$ & $r \cdot$ & بعدي & & \\
\hline \multirow[t]{2}{*}{$\cdot, \cdots 1$} & 19 & $10, .99$ & $\cdot, r r$ & $\cdot, .0$ & $r \cdot$ & قبلي & | ل درجة * & استقبال الإرسال من أسفل \\
\hline & & & $r, r_{1}$ & $\mathrm{v}, 10$ & $r \cdot$ & بعدي & & \\
\hline \multirow[t]{2}{*}{$\cdot, \cdots 1$} & 19 & $9,9+r$ & $1, \wedge \wedge$ & $r, \varepsilon \cdot$ & $r \cdot$ & 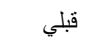 & 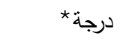 & الضرب الساحق المستقيم \\
\hline & & & $r, r V$ & $v, v$ & $r \cdot$ & بعدي & & \\
\hline \multicolumn{9}{|c|}{ 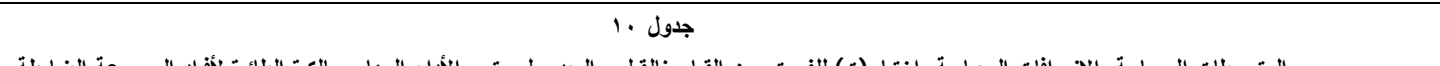 } \\
\hline \multicolumn{9}{|c|}{ المتوسطات الحسابية والاتحرافات المعيارية واختبار (ت) للفروق بين القياسينالقبلي والبعدي لمستوى الأداء المهاري بالكرة الطائرة لأفراد المجموعة الضابطة } \\
\hline دلالة احصائية & درجة الحرية & 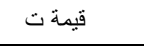 & $\varepsilon$ & س & ن & القياس & وحدة القياس & المهارة \\
\hline \multirow[t]{2}{*}{$\cdot, \cdots 1$} & 19 & T,TYK & $1, r v$ & r, ro & r. & 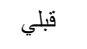 & د & ارسال من أسفل أمامي مواجهه \\
\hline & & & $1, r 4$ & $\varepsilon, \Gamma$ & $r \cdot$ & 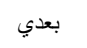 & & \\
\hline \multirow[t]{2}{*}{$\cdot, \cdots 1$} & 19 & $\neg, r \cdot v$ & $\cdot, \wedge 9$ & $\cdot, \wedge$ & $r \cdot$ & 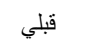 & | & الإرسال من أعلى (التنس) \\
\hline & & & $\cdot, \varepsilon 9$ & r, ro & $r$. & 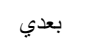 & & \\
\hline \multirow[t]{2}{*}{$\cdot, \cdots 1$} & 19 & $19,97 V$ & $\cdot$, vo & $\cdot$, ro & r. & 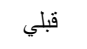 & | & الإعداد العالي لمركز ؛ \\
\hline & & & $\cdot$, vo & $\Gamma, \varepsilon$. & $r$. & بعدي & & \\
\hline \multirow[t]{2}{*}{$\cdot, \cdots 1$} & 19 & rT,ITE & 每, & $\cdot, r \cdot$ & r. & 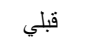 & | & استقبال الإرسال \\
\hline & & & $\cdot, 70$ & $\varepsilon, \cdots$ & $r \cdot$ & 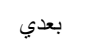 & & من أسفل \\
\hline \multirow[t]{2}{*}{$\cdot, \cdots 1$} & 19 & $r, T \cdot r$ & 1,17 & $1, v_{0}$ & $r$. & 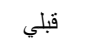 & | & ضرب ساحق مسنقيم \\
\hline & & & $\cdot, \wedge \uparrow$ & $r, \ldots$ & r. & بعدي & & \\
\hline
\end{tabular}

9 جدول 9

المتوسطات الحسابية والانحرافات المعيارية واختبار (ت) للفروق بين القياسين القبلي والبعدي للأداء المهاري بالكرة الطائرة للمجموعة التجريبية 
11 جدول

المتوسطات الحسابية والانحرافات المعيارية واختبار (ت) بين أفراد المجموعتين (التجريبية، والضابطة) في الاختبارات المهارية البعدية

\begin{tabular}{|c|c|c|c|c|c|c|c|c|}
\hline الدلالة الإحصائية & درجة الحرية & قيمة ت & $\varepsilon$ & س س & ن & المجموعة & وحدة القياس & المهارة \\
\hline \multirow[t]{2}{*}{$\cdot, \cdots 1$} & $r$. & $V, \varepsilon V \leq$ & $r, I \leq$ & $\Lambda, \leqslant 0$ & $r$. & تجريبية & درجة & الإرسال من أسفل \\
\hline & & & $1, r 4$ & $\varepsilon, r$. & $r$. & ضابطة & & \\
\hline$\cdot, \cdots 1$ & & & $\cdot, \leq 9$ & r, ro & r. & ضابطة & & \\
\hline$\cdot, \cdots 1$ & r. & $V, I V \varepsilon$ & $r, 0 \leqslant$ & $v, 70$ & $r \cdot$ & تجريبية & درجة & الإعداد العالي لمركز ؛ \\
\hline \multirow[t]{2}{*}{$\cdot, \cdots 1$} & r. & $V, \varepsilon \wedge \varepsilon$ & $r, r_{1}$ & $\mathrm{~V}, \wedge \mathrm{O}$ & $r \cdot$ & تجريبية & درجة & استقبال الإرسال \\
\hline & & & $\cdot, 70$ & $\varepsilon, \ldots$ & r. & ضابطة & & \\
\hline \multirow[t]{2}{*}{$\cdot, \cdots 1$} & r. & $\wedge, 70$ & $r, r V$ & $\vee, v$. & r. & تجريبية & درجة & الضرب الساحق المستقيم \\
\hline & & & $\cdot, \wedge т$ & $r, \ldots$ & $r \cdot$ & ضابطة & & \\
\hline
\end{tabular}

بالكرة الطائرة، يعزو الباحثان ختسن أفراد الجهموعة

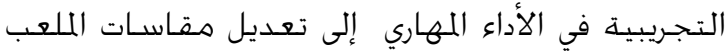

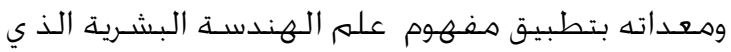

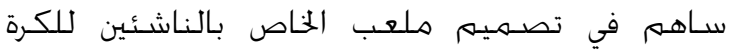

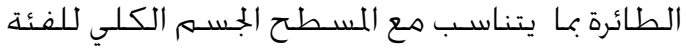

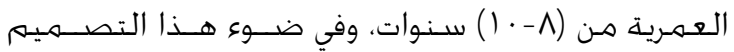

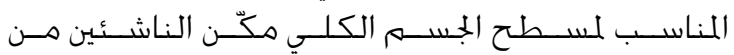

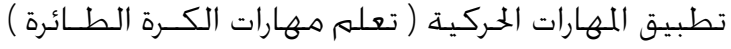

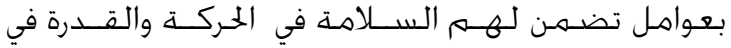

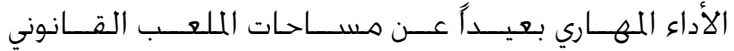

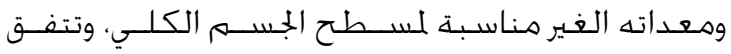

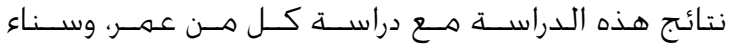

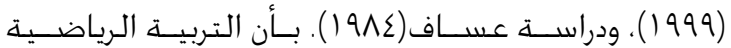

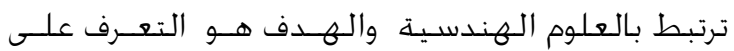

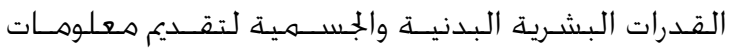

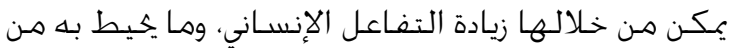

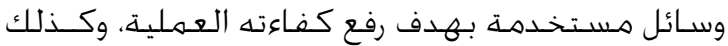

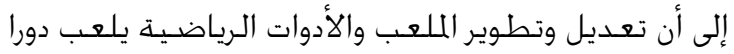

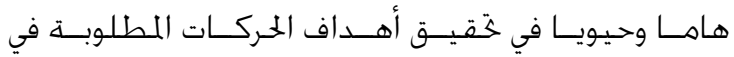

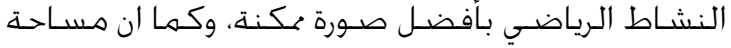

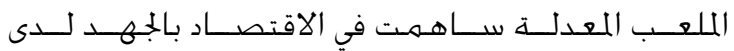

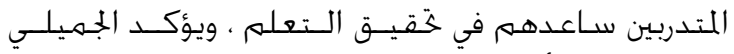

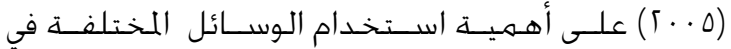

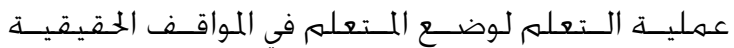

للعبة.

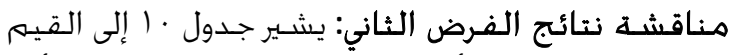

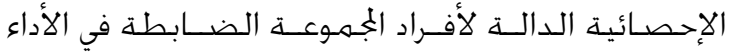

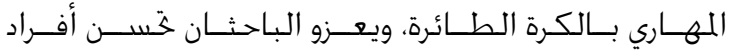

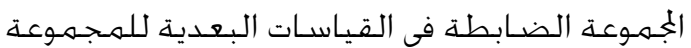

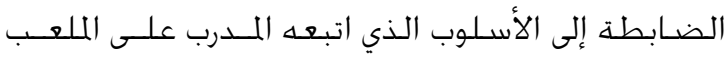

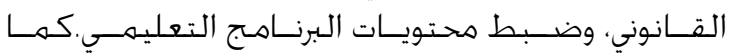

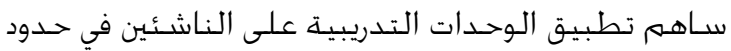

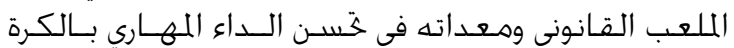

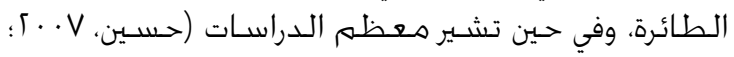

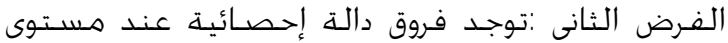

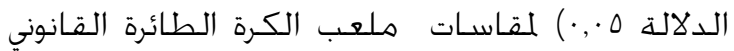

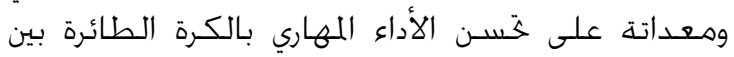

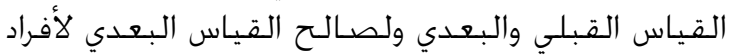
الجمهموعة الضـابطة.

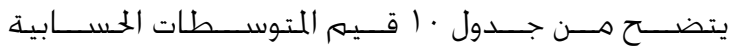

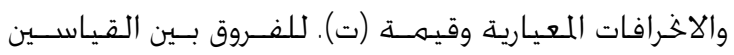

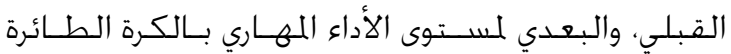

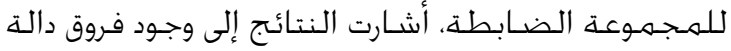

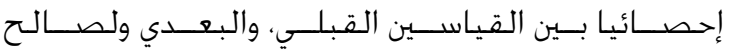

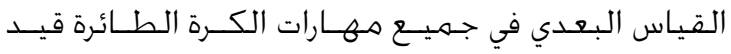

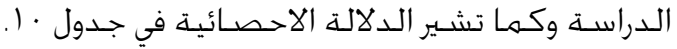

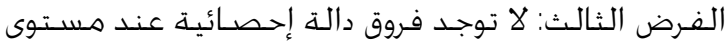

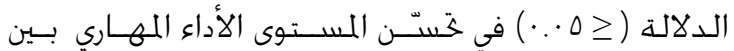

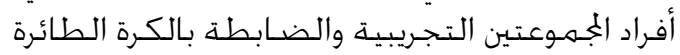

يوضسح جـدول (ا قيم المتوسـات الحسبابية والاخـرافات

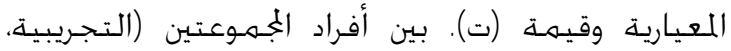

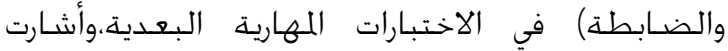

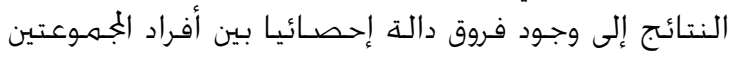
(التجريبية، والضـابطة)، في الاختبارات المهارية البعدية.

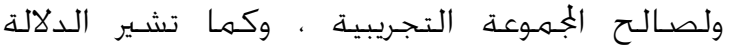
الاحســائية في الجـدول.

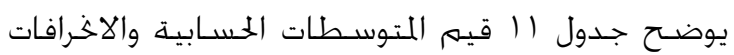

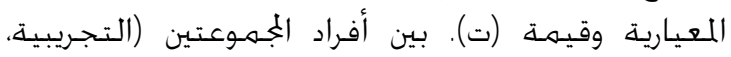

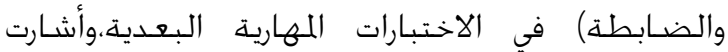

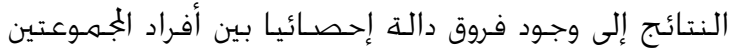
(التجريبية، والضـابطة)، في الاختبارات المهارية البعدية.

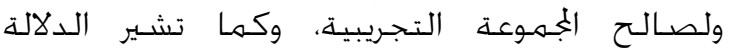
الاحســائية في الجـدول.

\section{مناقشة النتائج}

\section{مناقشـــ نتائج الفرض الأول:}

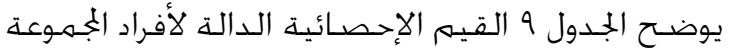

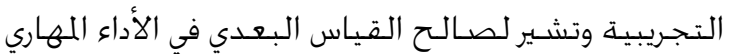




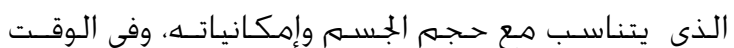

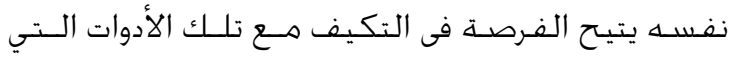

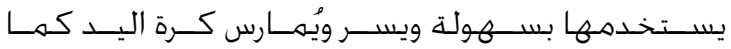

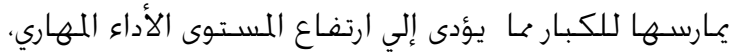

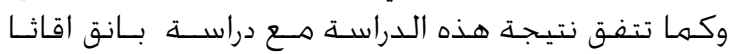

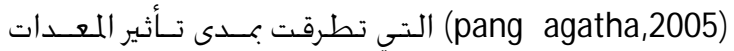

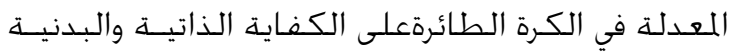

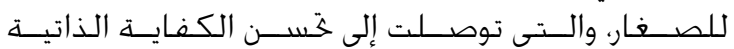
والبـنيـة للصغار.

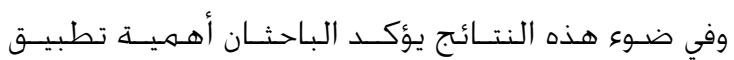

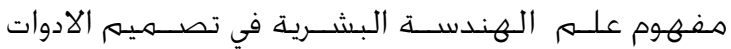

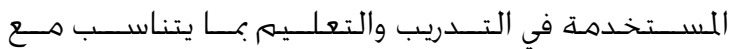

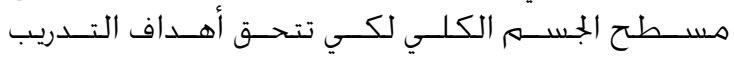

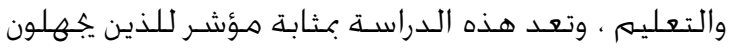

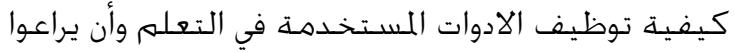

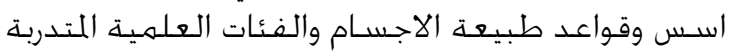
في مجال الكـرة الطائرة.

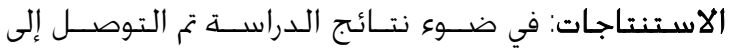

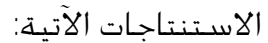

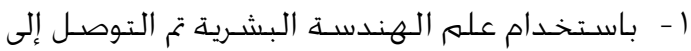

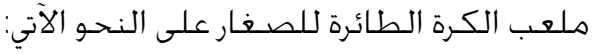

\begin{tabular}{|c|c|}
\hline مار.q. & الطــــــــول \\
\hline م 1,90 & العـــــــرض \\
\hline م & المنطقـة الأمامية \\
\hline $\mathrm{e}^{\Sigma, 1 \mu}$ & المنطقة الخلفية \\
\hline م & ارتفـاع الشـبكـة \\
\hline & ارتفاع الهوائيهُ, م م \\
\hline & طول القـوائم 1,9Vم \\
\hline & 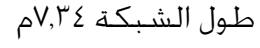 \\
\hline$\Delta \Sigma, \Gamma \Sigma$ & وزن الكـرة \\
\hline
\end{tabular}

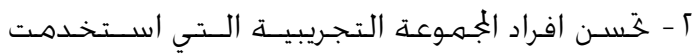

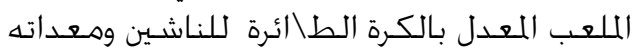

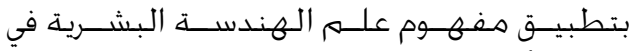
تعلم الأداء المهاري بالكـرة الطائرة.

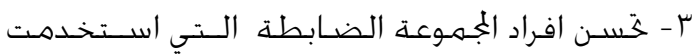

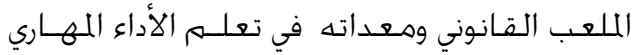
بالكـرة الطائرة.

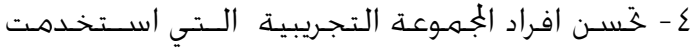

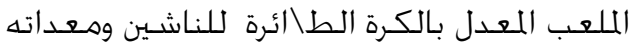

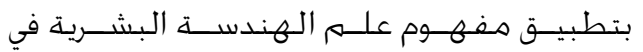

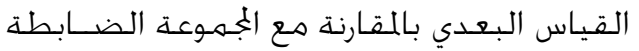

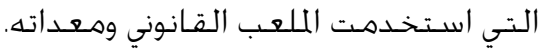

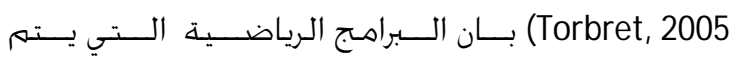

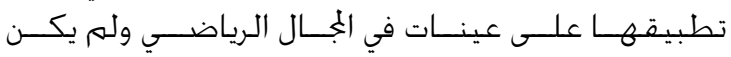

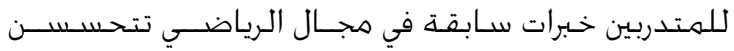

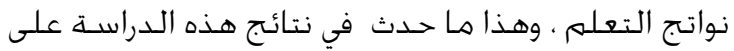

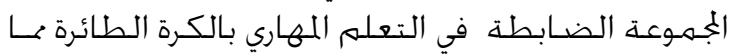

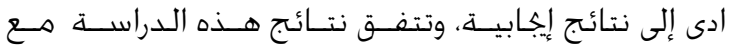

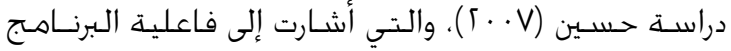

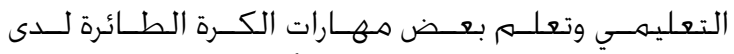

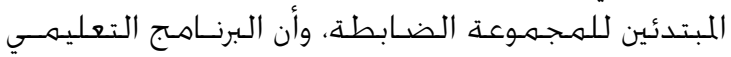

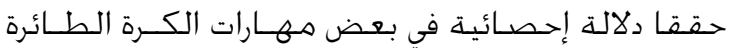

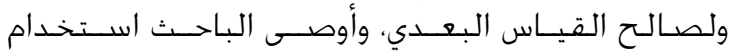

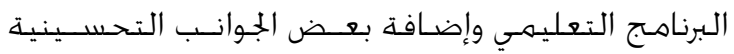

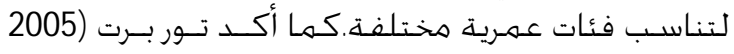
(Torbret,

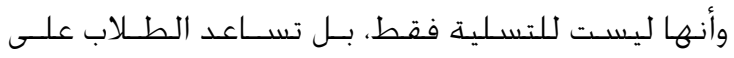

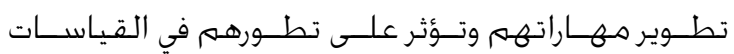
البعدية.

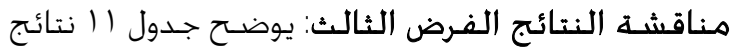

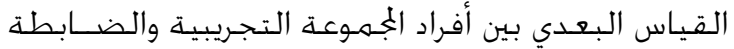

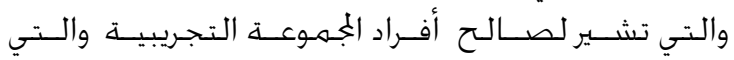

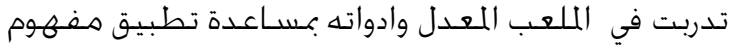

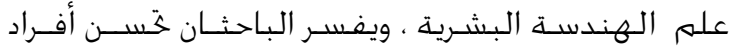

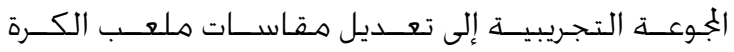

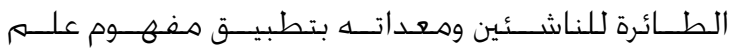

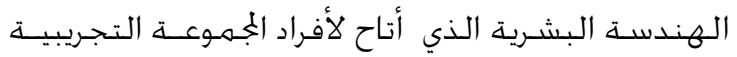

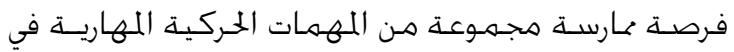

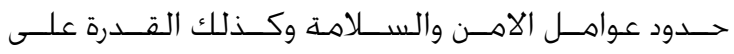

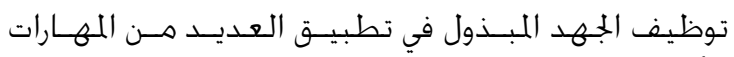

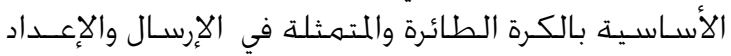

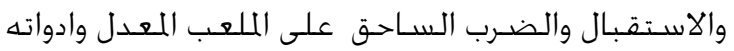

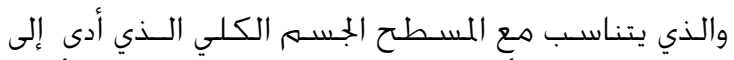

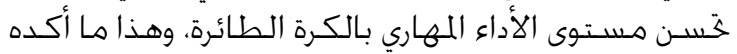

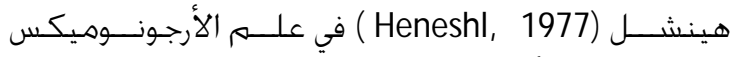
Ergonomics

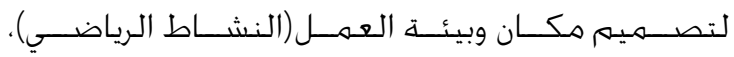

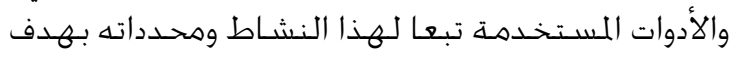

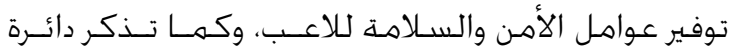

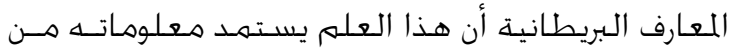

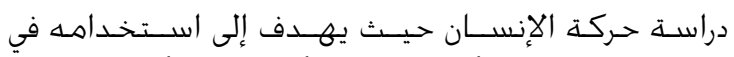

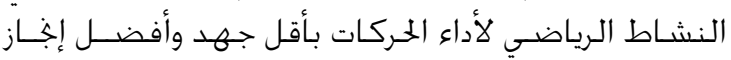

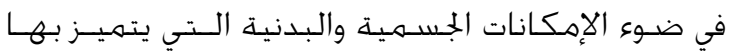

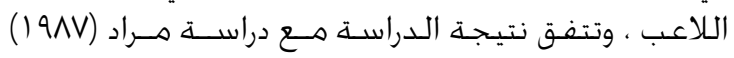

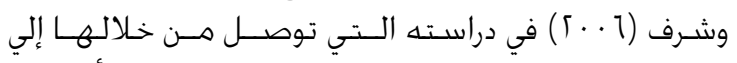

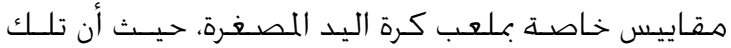

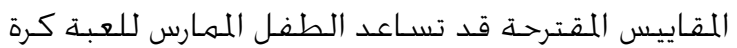

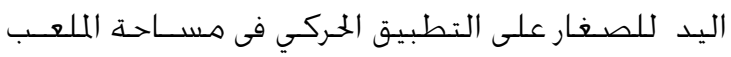


الخطايبة، أكرم (997). موسـوعة الكرة الطائرة الحديثة. عـمان: دار الفكر للطباعة والنشـر.

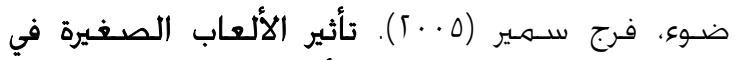

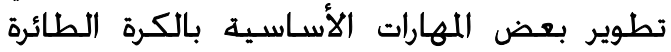

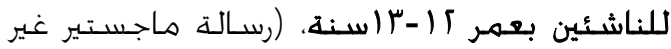

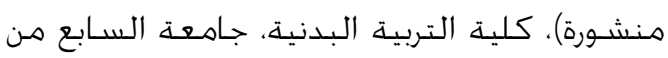
ابريل ، الزاوية، ليبيا.

طه، علي مصطفى (999 ). الكرة الطائرة، تعليم، تاريخ،

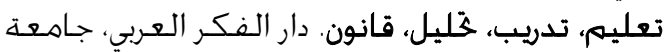
حلوان.

شـرف، عبد الخميد (1 ا). التربية الرياضية والحركية

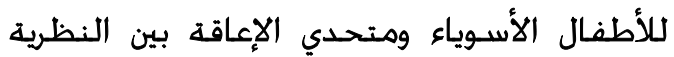

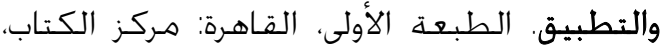

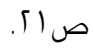

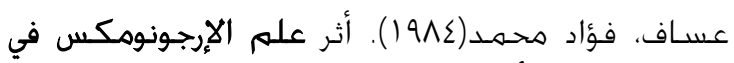

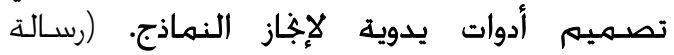

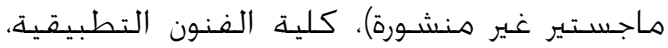
جامعة حلوان، مصـر.

عمهر، شـكري، وإبراهيه، سـناء (991)). تعديل مقاسـات ملعب كرة السلة للصغار (الميني باسكت) وفتاً لقواعد علم الهندسـة البشرية وأثره على الأداء

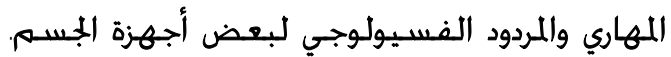

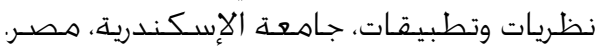

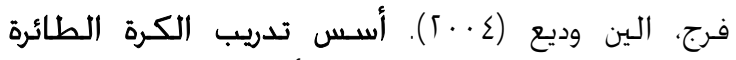

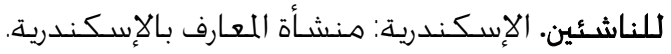
مـراد، جـمال الدين عبد العزيز (9^V9 () ). تعديل قانون كرة

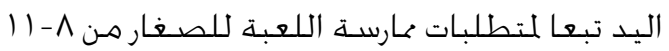

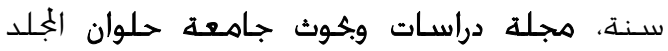

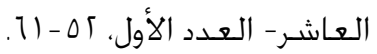

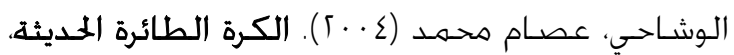

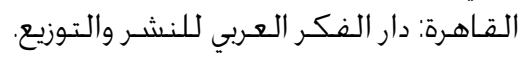

\section{المراجع الأجنبية:}

Boyd, E. (1935). The growth of the surface area of the human body. Minneapolis: University of Minnesota Press. From:

http:/ / www.ispub.com/ journals/ IJA/ Vol2N2 /bsa.htm

Dubois D., Dubois E. F. (1916). A formula to estimate the approximate surface area height and weight be known. Arch Int M ed 17, 863 871.

Fraser, S. (1988). Strateger for cooperative volleyball. Champaign II: Leisure press.
التوصيات:

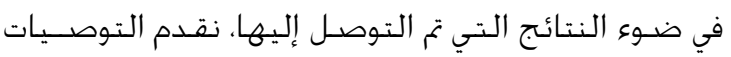
الآتية: التية

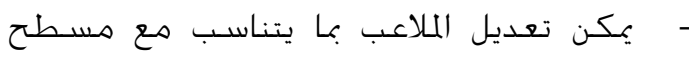

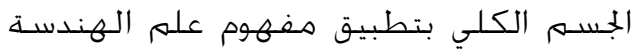
البشـرية).

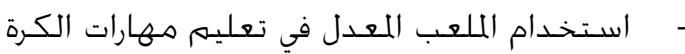

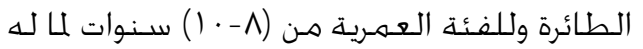
هـن أثر واضـح في ختسـن مهارات الكـرة الطائرة. تزويد الاختاد الاردني والدولي بنتائج هذه الدراســــ وذلك لأهـميتها في هذا الإلـال.

\section{المبر اجع}

المراجع العربية: - المر

إبراهيم، مـروان عبد الجيد (1999). الأسس العلمية والطرق الاحصائية للاختبارات والقياس في التربية الرياضية. عمان: دار الفكر للطباعـة والنشـر والتوزيع. إبراهيه، مروان عبد الجيد (1 . ؟) الموسـوعة العلمية في

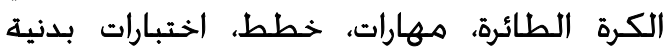

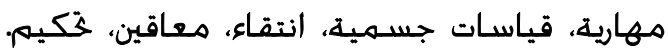
عـمان: مؤسـســة الوراقين.

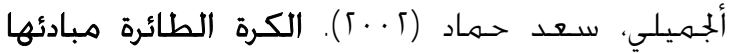

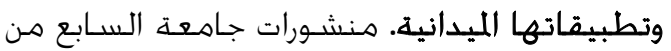

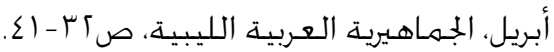

الجـميلي، عبد الاله ناجي ونعيمة، عبد السـلام (ه ؟). أثر

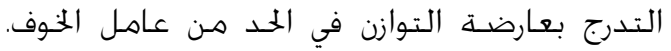

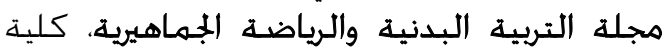

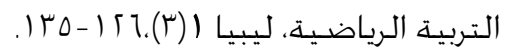

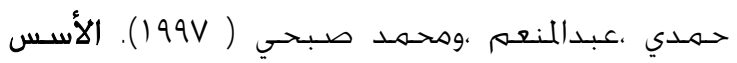
العلمية للكرة الطائرةً طرق القياس، بدني، مهاري،

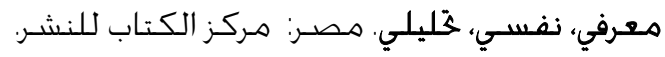

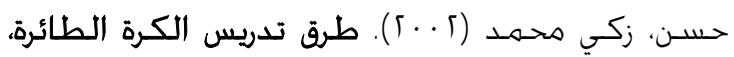

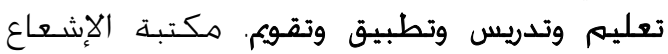

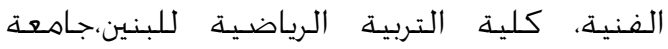

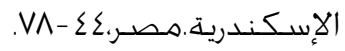

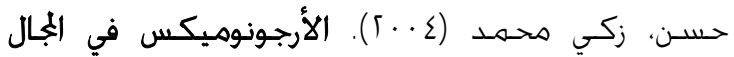

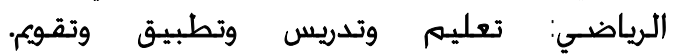

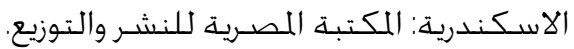

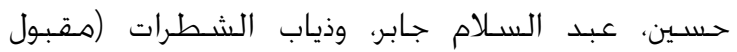

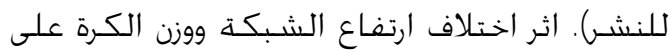

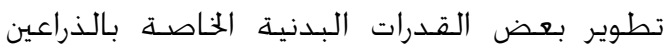

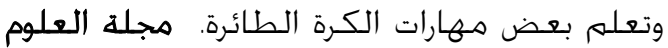
التربوية والنفسية. 
Georgieff, B. (2006). Anthropometric and Behrman, A. How A bout That Whole Child? Independent School, 65 (1). 144-171

Haycock G.B., Schwartz G. J.,Wisotsky D. H.(1978). Geometric method for measuring body surface area: A height weight formula validated in infants, children and adults. The Journal of Pediatrics, 93, 62-66

Pang, A. (2007). Effects of regular and modified volleyball equipment on skill performance and self-efficacy of Hong Kong children. ICHPER SD Journal, 41 (1), 13-18.

Samders, M. S. \& Mccoormik, E. J. (1993). Human factors in engineering and design. New York: Mcgraw-Hill.

Torbert, Marianne (2005). Using active group games to develop basic life skills. Journal of Young Children, 60 (2) 72-78.: From: http:// web.ebscohost.com 